\title{
Associations of Smartphone and Tablet Use in Early Childhood with Psychosocial, Cognitive and Sleep Factors: A Systematic Review and Meta-Analysis
}

\author{
Sumudu R. Mallawaarachchi, Jeromy Anglim, Merrilyn Hooley, Sharon Horwood ${ }^{1}$
}

\begin{abstract}
The current study provides the first systematic review and meta-analysis of the associations of smartphone and tablet use with psychosocial, cognitive, and sleep-related factors in early childhood development. The meta-analysis aimed to provide an overall assessment of the evidence while the systematic review offered a rich overview of the methodological approaches adopted to assess these associations. Studies were included in the review if they examined the association of smartphone or tablet use with a measure of psychosocial development, cognitive development, or sleep in toddlers or preschoolers. Out of 1050 articles that were initially identified, 26 studies were included in the final sample of the systematic review, of which 19 were included in the meta-analysis. Data were screened, extracted, and synthesized according to PRISMA guidelines. A random-effects meta-analysis of correlations found a significant yet weak association of increased smartphone and tablet use with poorer overall child developmental factors. Additionally, a similar but stronger association was found between parental perceptions of problematic device use and poorer overall child factors. Meta-correlations with device use were significant for sleep, but not for psychosocial and cognitive factors. Overall, the results suggest that longitudinal cohort and experimental investigations would elucidate more causal relationships of child factors with smartphone and tablet use. Employing multiple methods of screen-use assessment, and considering the multiple levels of proximal and distal influences on child smartphone and tablet use, would also be useful. Adopting more rigorous research practices in the future, will facilitate deeper insights into the potential developmental implications of smartphone and tablet use in early childhood.
\end{abstract}

Keywords: screen media, mobile devices, early childhood, child development, child behavior

\section{Citation:}

Mallawaarachchi, S. R., Anglim, J., Hooley, M., \& Horwood, S. (2022). Associations of smartphone and tablet use in early childhood with psychosocial, cognitive and sleep factors: a systematic review and meta-analysis. Early Childhood Research Quarterly, 60, 13-33. https://doi.org/https://doi.org/10.1016/j.ecresq.2021.12.008 
Correspondence concerning this article should be addressed to Sumudu Mallawaarachchi, School of Psychology, Deakin University, Locked Bag 20000, Geelong, 3220 Australia. Email: smallawaarachch@deakin.edu.au

\section{Introduction}

Since the debut of the iPhone in 2007, smartphones and tablets have gained immense popularity among children of increasingly younger ages (Barr et al., 2018; Rhodes, 2017; Smith \& Page, 2015; Wartella et al., 2013). In 2019, at least one-third of US preschool children by the age of three years had access to a dedicated mobile device which they used, on average, approximately two hours per day (Radesky et al., 2020). The increase of smartphone and tablet use during early childhood years has raised concern about potential problematic use, yet the rapid pace of technology uptake currently outstrips research examining the potential benefits and harms associated with childhood use of screens (Radesky et al., 2015). The toddler (age 1 to 3 years) and preschool years (age 3 to 5 years) are important periods of psychosocial and cognitive development, typically characterized by large amounts of brain plasticity (Fox et al., 2010; Jimenez et al., 2016; Shonkoff, 2010). Early childhood years may also influence life-long screen habits, similar to other health-related behaviors such as diet and physical activity (Radesky \& Christakis, 2016). To better understand the potential harms and benefits of smartphone and tablet use in young children, the present study provides a systematic review and meta-analysis of research examining the relationships of smartphone and tablet use with psychosocial, cognitive and sleep-related factors in young children.

\section{Child Development in Toddlers and Preschool Children}

Child development during the early years is a dynamic sequence of maturation that is influenced by family and social environments, and individual characteristics of the child. Aspects of psychosocial and cognitive development, such as maturation in thinking, regulating emotions and behavior, reasoning, problem-solving and communication (Sigelman \& Rider, 2014) are key areas of early childhood development that are crucial for effective integration into the social world. For example, gaining the ability to understand and follow simple instructions by 12-18 months, having a spoken vocabulary of about 20 to 300 words by 18-24 months, turn taking and sharing by 3 years, and perspective taking by 4 years are examples of typical cognitive and psychosocial milestones achieved during early childhood (Petty, 2016). Milestone achievement 
is promoted through various stimulating behaviors such as physical activity (Hinkley et al., 2014; LeBlanc et al., 2012), active exploration of natural environments (Sigelman \& Rider, 2014), social interactions with caregivers (McCabe \& Altamura, 2011), and child-led creative, unstructured or pretend play (Burdette \& Whitaker, 2005; Ginsburg, 2007; Lillard et al., 2013).

Children who have an inadequate opportunity to interact with their environment can fail to meet developmental milestones, and this may cause further challenges in acquiring other necessary cognitive, social, and emotional skills (Sigelman \& Rider, 2014; Trawick-Smith, 2013). In extreme cases, children suffering severe neglect can fail to develop language, motor, and socio-emotional skills necessary for normal functioning (e.g., Carr et al., 2020); however, in less extreme cases, interference to healthy development may result in adverse outcomes such as self-regulation difficulties (Phillips \& Shonkoff, 2000), social withdrawal (Rubin et al., 2009), poor literacy and communication abilities (Horwitz et al., 2003; Paul et al., 1991), and physical health problems such as obesity (Suglia et al., 2012, 2013). Although some difficulties may not be severe enough to receive clinical attention, they are likely to reduce the benefit that children derive from education (Janus \& Offord, 2007).

\section{Role of Smartphones and Tablets in Child Development}

Child development research has long sought to identify factors that interfere with healthy development. Screen time has received considerable attention (Madigan et al., 2019; Radesky \& Christakis, 2016), with most screen time research focused on the effect of traditional screen media (e.g., television, video gaming consoles) on young children's well-being and development (e.g., Hinkley et al., 2014; Madigan et al., 2019; Madigan et al., 2020; Radesky \& Christakis, 2016; Thompson \& Christakis, 2005; Zimmerman \& Christakis, 2005; Zimmerman et al., 2007). However, the potential for smartphone and tablet use to adversely affect development in early childhood has been given relatively less attention. Smartphones and tablets have become very appealing to young children (Kabali et al., 2015; Paudel et al., 2017), possibly due to their unique features such as portability, interactivity, internet access, and multi-functionality (Wartella et al., 2013). Their smaller size and hand-held nature also permit more solitary use, making parental supervision and monitoring more difficult (Radesky \& Christakis, 2016). However, it is not clear whether the influence of smartphone and tablet use on children's wellbeing and development is more pronounced and persistent than that of traditional screen media (Haughton et al., 2015). 
Several studies have found that use of interactive smartphone or tablets apps in early childhood can have developmental benefits such as improved development of fine-motor skills (Bedford et al., 2016; Vatavu et al., 2015), executive functioning (Huber et al., 2018), and science/mathematics learning and problem solving (see Herodotou, 2018; Xie et al., 2018 for reviews). Chiong and Shuler (2010) further suggested that when used in moderation, the benefits for young children can be optimized through well-designed, developmentally appropriate educational apps. The positive learning effects were found to be content-dependent however, and limited to mainly interactive educational apps (i.e., not passive viewing; Huber et al., 2016). However, as these studies have been predominantly conducted with smartphone or tablet use as an experimental condition (Lawrence \& Choe, 2021), the extent of the positive effects and the point at which naturalistic or habitual use may become problematic (i.e., when harms outweigh the benefits), is yet to be investigated.

Domoff et al. (2020) have proposed a theoretical framework that outlines multiple levels of influence on children's problematic screen use. The model identifies proximal influences (e.g., child behavior and skills, parent beliefs and practices) and distal influences (e.g., demographics, parent use of technology, technological features) that are theorized to interactively influence early childhood screen use. The framework, adapted from Bronfenbrenner and Morris' (2007) bio-ecological model, proposes that smartphone and tablet use can be bi-directionally associated with child- and parent-related factors. For example, the child-specific skill of self-regulation (proximal factor) could be considered a predictor of screen time when considered in concert with the enticing technological features and portability of smartphones and tablets (distal factors). Together, poor self-regulation and attractive technological features may make it difficult for young children to naturally limit their own screen time, and potentially increase resistance to parental attempts to limit screen time. Conversely, screen time could, in theory, impair development of self-regulation. This could be possible if screen time displaces developmentally necessary and productive language-rich social interactions or opportunities for outdoor play (Radesky et al., 2015). Similarly, parents may in some cases rely on screens to soothe a distressed child. Effectively using a smartphone or tablet to regulate behavior could result in more frequent and prolonged episodes of childhood screen use as parental beliefs about the convenience of device use strengthen (Haughton et al., 2015; Radesky et al., 2015; Radesky et al., 2014). Past studies have found that using smartphones or tablets as "electronic pacifiers", 
“electronic babysitters" or "shut-up toys" (Radesky et al., 2015) is associated with the development of self-regulatory mechanisms. Parents may also control their child's free/outdoor play in response to their own anxiety about child safety. Studies that have examined the ideas of 'cotton wool' children and 'helicopter parenting' illustrate this pattern of hyper-cautious parental thinking (e.g., Lee et al., 2010), which may influence parents' decision-making about when and how often to substitute outdoor play with digital play on smartphones and tablets.

Although there is now an emerging body of research on young children's smartphone and tablet use in early childhood, there is value in an evaluative synthesis of the current literature. For instance, the early childhood smartphone and tablet use literature concerning psychosocial or cognitive factors have reported positive associations (e.g., Huber et al., 2016; Neumann \& Neumann, 2017), negative associations (e.g., Cheung et al., 2017; Lin et al., 2020), and no association (e.g., McNeill et al., 2019; Taylor et al., 2017). To develop clear directions for ongoing research in this area, it is important to assess the collective findings so as to draw inferences about the associations that may exist between young children's smartphone and tablet use and their psychosocial and cognitive factors. Additionally, sleep-related factors such as onset and duration should be included in any review of the literature, given the important role of sleep in childhood psychosocial (Anders, 2004; Sadeh, 2003; Zhao et al., 2018) and cognitive (Hoyniak et al., 2020; Kocevska et al., 2017) development.

Past systematic reviews of the early childhood years have not focused on relationships between smartphone or tablet use and child-specific factors in psychosocial, cognitive and sleep domains. Instead, some have focused on other aspects of screen use such as sedentary screen time (Carson et al., 2016; Hinkley et al., 2014; LeBlanc et al., 2012), television viewing (Kostyrka-Allchorne et al., 2017; Thakkar et al., 2006), and combined traditional and modern screen media use (Duch et al., 2013; Kaur et al., 2019) in relation to the same domains. Despite a growing body of evidence concerning smartphone and tablet use in young children (e.g., Kabali et al., 2015; Levine et al., 2019; Radesky et al., 2015), to date only one review by Paudel et al. (2017) has examined correlates associated with smartphone and tablet use in early childhood. They focused on demographic and environmental correlates of smartphone and tablet use, which are considered distal factors within the Domoff et al. (2020) interactional framework.

\section{The Current Study}

To our knowledge, no review or meta-analysis has examined or synthesized the empirical 
literature on the associations of smartphone and tablet use with proximal child-specific factors in the psychosocial, cognitive, and sleep domains of early childhood development. Further, a systematic review offers both an in-depth understanding of the methodological approaches within studies, and a timely opportunity to highlight existing gaps and methodological shortcomings in this emerging area to present future research recommendations.

Therefore, we posed the following research question; what associations exist between smartphone and/or tablet use and psychosocial, cognitive and sleep-related factors, in toddlers and preschoolers? In addressing this research question, first, the systematic review sought to provide a rich overview of methodological approaches used in this literature to help generate insights into factors that might explain variations in study findings. Second, the meta-analysis sought to provide an overall synthesis of the current estimates of the strength of association between study variables.

\section{Method}

\section{Protocol}

The protocol of the review was registered with PROSPERO Prospective International Register for Systematic Reviews (Registration number: CRD42020185907; URL: https://www.crd.york.ac.uk/prospero/display_record.php?ID=CRD42020185907). The PRISMA guidelines for reporting of systematic reviews were followed in preparation of this manuscript (see supplement S9; Moher et al., 2011).

\section{Eligibility Criteria}

For a study to be included in the review, it needed to satisfy the following five criteria (see Table S1 for further details). First, the study needed to be published after January 2007 and before November 2020, when the final search was conducted. The 2007 cutoff corresponds to the debut of iPhones and the beginning of widespread use of smartphones (Sarwar \& Soomro, 2013). Second, the study needed to focus on non-clinical populations of children aged between 1 and 6 years and prior to primary school entry. Third, it needed to include a dedicated measure of children's smartphone use, tablet use, or combined mobile device use with a predominant focus on smartphones/ tablets. Fourth, it needed to include a measure of child psychosocial, cognitive, or sleep characteristics. Finally, it needed to provide quantitative measures of association in a naturalistic setting. Smartphone-related interventions and experimental studies, which included smartphone or tablet use as an experimental group, were excluded. 


\section{Search and Information Sources}

Systematic searches using PsycINFO, Medline Complete, EMBASE and CINAHL were conducted for original research articles published between January 2007 and November 2020. Medline Complete and EMBASE were chosen as they have been recommended as essential health databases (as two of the largest) by the Cochrane guidelines (Higgins et al., 2020). PsycINFO and CINAHL were selected as the subject-specific databases due to the direct relevance of psychology and nursing (allied health), respectively, to the research topic. For completeness, we also piloted the search on the ERIC database but found that it identified no additional articles. Searches were performed on title, abstract, and subject headings for articles containing at least one match in the following three categories: (a) smartphone or tablet use, (b) child psychosocial or cognitive or wellbeing or development or sleep, and (c) toddler or preschool children. Example search terms were (smartphone* OR "mobile device*" OR ipad*") AND (e.g., "child behavi*" OR social OR emotion* OR cogniti*) AND (e.g., preschool* OR toddler* OR "young child*"). The full search strategy used in PsycINFO is provided in Table S2. Additional articles were identified by examining the reference lists and subsequent citations of key articles.

\section{Study Selection}

Articles identified by the search process were imported into Endnote X9 and duplicates were deleted. Remaining articles were imported into Covidence systematic review software (Veritas Health Innovation, available at www.covidence.org) and titles and abstracts were screened by the first and second authors to identify articles for full-text screening. Full-text screening of the eligible articles was conducted by both the first and second authors to determine final eligibility for inclusion in the review synthesis. Conflicts over study inclusion were resolved through critical discussion, cross-checking with criteria in the protocol, and consultation with the third and fourth authors. Inter-rater agreement rates for the screening processes are provided in the 'Study Selection' section of the Results.

\section{Methodological Assessment}

Methodological quality and risk of bias was assessed using the Quality Assessment Tool for Observational Cohort and Cross-sectional Studies (National Heart, Lung and Blood Institute, 2014). This tool was used to assess the relevance to the review question, methodological rigor, and risk of bias at the study and variable level following guidelines set out by the National Heart, 
Lung, and Blood Institute (NHLBI; See Table S3). This assessment was conducted independently by the first and second authors, with consensus reached for any inconsistencies in scoring directed by the NHLBI guidelines, following the approach adopted by meta-analyses in the area of screen time (e.g., Adelantado-Renau et al., 2019; Madigan et al., 2020). The tool comprised 10 criteria including clarity of research question, appropriateness of study design, clarity of sample, appropriateness of measurements and analyses that were rated as either low or high-risk of bias. Examples of items that have been assigned a rating of 'high' or 'low' risk of bias for each criterion are provided in Table S3. Each study was classified as (a) low risk of bias [0 or 1 bias markers], (b) moderate risk of bias [2 or 3 bias markers], (c) high risk of bias [4 or more bias markers].

\section{Data Extraction and Narrative Synthesis}

Following quality assessment, data extraction was independently undertaken by the first and second authors using a piloted data extraction template (see Table S4). The following data were extracted: (a) study design, (b) sample size, (c) other sample characteristics, (d) measure of use of smartphones, tablets or both, (d) measure of child-specific factors (i.e., psychosocial, cognitive, or sleep-related), (e) main findings regarding the association of smartphone and tablet use with child factors, and (e) what, if any, covariates were examined. For the narrative synthesis, the child-specific factors were conceptualized into the three domains: psychosocial, cognitive, and sleep. Psychosocial factors related to the development of child's socio-emotional competence and ability to maintain relationships. Cognitive factors involved thinking, reasoning, language, and literacy-related variables. Sleep factors included variables related to the quantity and quality of sleep.

\section{Data Analysis for Meta-Analysis}

As the final sample of studies largely included linear relationships which were crosssectional in nature and given the heterogeneity in covariates used in adjusted analyses, metaanalysis of correlations was deemed the most appropriate summary statistic. Where available, correlation coefficients were extracted for each study. The direction of the coefficient was reversed for negative variables such as speech delay, internalizing/ externalizing behavior, and sleep problems so that all variables were positively aligned with wellbeing or development. Sixteen corresponding authors were contacted via email for additional information on correlations between relevant variables, of which seven provided this information. If 
standardized regression coefficients were reported instead of correlation coefficients, they were converted to correlation coefficients using formula described by Peterson and Brown (2005). When multiple groups were drawn from the same dataset, the data were analyzed as independent samples. If multiple effect sizes for comparable factors within the same domain were available for the same study, they were aggregated by averaging (Borenstein et al., 2009) to only include one effect size from each study. If there were multiple effect sizes from the same study belonging to different domains in the high-level meta-analysis of associations between amount of use and overall child-specific factors, the robust variance estimation approach (RVE; Hedges et al., 2010) was used to account for any within-study dependencies.

A random-effects meta-analysis was conducted given that correlations were expected to vary based on sample, measurement, design, and other characteristics (Borenstein et al., 2009). The meta-analysis was conducted in R using the "metafor" package (Viechtbauer, 2010), with alpha levels of .05 (i.e., $p<.05$ ), considered to be statistically significant. The "robumeta" package (Fisher \& Tipton, 2015) was further used to carry out the high-level RVE analysis of association between amount of use and overall child-specific factors, accounting for multiple effect sizes from same study and small number of studies available. The moderating effects of the variables (a) time period (year range) of publication (given the rapid adoption of mobile technology across the years) and (b) quality of study (given the variation in risk of bias and quality among studies) were tested using supplementary moderation analyses also conducted in R using the "metafor" package. These supplementary moderation analyses were conducted to determine how much each of these variables may contribute to the observed variability of effect sizes between studies (Quintana, 2015). Heterogeneity across studies was assessed using tau ( $\tau$; the estimated standard deviation of underlying effects across studies) and $I^{2}$ statistics ( $I^{2}$ values of $25 \%, 50 \%$ and $75 \%$ considered as low, moderate and high, respectively) (Borenstein et al., 2009). Egger regression asymmetry test, funnel plots and rank tests were conducted to assess publication bias, with $p<.05$, considered to be statistically significant (Quintana, 2015). All scripts and data for the meta-analyses are available on the OSF: https://osf.io/5zka6/?view_only=9773162de4de48c398b6df0f00579d0c

\section{Results}

\section{Study Selection}

Figure 1 provides the PRISMA flow diagram for study inclusion. Following removal of 
duplicates, 1,050 unique articles were identified for title and abstract screening. An inter-rater agreement rate of 90 (Cohen's $\kappa=.44$ ) was established during the abstract screening process. Abstract screening identified 83 articles that potentially met the inclusion criteria and were progressed to full-text screening. An inter-rater agreement rate of .82 (Cohen's $\kappa=.62$ ) was maintained during the full-text screening process. Following full-text screening, assessment of quality, methodological relevance and risk of bias, a final sample of 26 articles were included in the narrative synthesis. Of the final eligible articles, published and unpublished data from 19 articles were included in the meta-analysis (See Tables 1, 2 and 3).

\section{Study Characteristics}

\section{Methodological Assessment}

A detailed risk of bias assessment is presented in the online supplement (see Table S3 and Table S5). Of the 26 articles reviewed, risk of bias ratings were as follows: low $(N=4$; $15 \%)$; moderate $(N=19 ; 73 \%)$; and high $(N=3 ; 12 \%)$. Most studies were cross-sectional with only three studies (McDaniel \& Radesky, 2020; McNeill et al., 2019; Poulain et al., 2018) using longitudinal designs. In terms of exclusively measuring use of smartphones and tablets, one article (Borajy et al., 2019) did not include detailed reporting of screen time, another study (McNeill et al., 2019) assessed type of use (i.e. app use) rather than amount of overall use in relation to smartphone and tablet use, while three studies (Lan et al., 2020; Levine et al., 2019; Poulain et al., 2018) aggregated portable media such as iPods or hand-held videogames with smartphones and tablets. Only ten studies reported pre-determined eligibility criteria prior to recruitment, taking into account various developmental variances and other clinical conditions in young children that may differentially influence their development and potentially influence their smartphone and tablet use. Nine studies did not adjust for potential covariates (e.g., demographics). Further, one study (Cannoni et al., 2018) was dropped from the review because it did not use a validated or standardized instrument for measurement of child-specific factors and included limited statistical analyses (chi-squared analysis only).

\section{Sample Characteristics}

Details on the sample, measures used, key findings and the covariates examined in each article in the psychosocial, cognitive, and sleep domains respectively are shown in Table 1, Table 2 and Table 3. Altogether, there were 24 samples with a combined sample size of 11,515. Most articles $(N=19 ; 73 \%)$ were published since 2018 with the remainder published from 2014 
to 2017 . In terms of study design, most were cross-sectional $(N=23 ; 89 \%)$ while only $3(11 \%)$ were longitudinal. The most common countries for conducting studies were the United States $(N$ $=7 ; 27 \%)$, South Korea $(N=5 ; 19 \%)$, Australia $(N=2 ; 8 \%)$, and the United Kingdom $(N=2$; $8 \%$ ). In terms of child factors examined in articles, noting that some articles examined more than one, 13 examined psychosocial factors, 10 examined cognitive factors, and 7 examined sleep. Of these, four articles which examined psychosocial factors also examined cognitive factors (Lin et al., 2020; McNeill et al., 2019; Moon et al., 2019) and sleep (Nathanson \& Beyens, 2018b).

The mean ages of the included samples ranged from 1.43 years (17.14 months) to 5.42 years (with only one sample of preschool children in Turkey with a mean age $>5$ years; Gülay Ogelman et al., 2016). Most articles $(N=17 ; 62 \%)$ consisted of samples of only preschool children (defined as above 3 years and prior to primary school entry), but some articles $(N=7$; 27\%) examined only toddlers (defined as aged 1 to 3 years), or combined toddlers and preschoolers $(N=2 ; 8 \%)$. Sample sizes ranged from 56 (Lawrence et al., 2020) to 2,903 (Lan et al., 2020). Among the final sample of included studies, three articles (i.e., Beyens \& Nathanson, 2019; Nathanson \& Beyens, 2018a, 2018b) included the same dataset and sample. All three articles were included in the narrative review as three different exposure-outcome relationships were examined, i.e., smartphone and tablet use in relation to (a) sleep quantity, bedtime resistance and daytime sleepiness (Nathanson \& Beyens, 2018a), (b) sleep and effortful control (Nathanson \& Beyens, 2018b), and (c) napping behavior and sleep consolidation (Beyens \& Nathanson, 2019). However, only one effect size was used for the meta-analysis from the dataset.

\section{Smartphone, Tablet, and Child-Factor Measurement}

All studies measured smartphone and tablet use in children using reports by parents or primary caregivers. Smartphone and tablet use was primarily operationalized as frequency (e.g., number of times the device is used per week; $N=4 ; 15 \%)$ or duration of use (e.g., time spent on device in hours per day; $N=17 ; 65 \%$ ). The timing of device use (e.g., whether they were used around bedtime) was measured in one sample (Beyens \& Nathanson, 2019; Nathanson \& Beyens, 2018a, 2018b). Five studies measured parental perceptions of excessive or problematic use by young children, using various terminology including smartphone addiction proneness (Cho \& Lee, 2017), addiction tendency (Lee et al., 2015), over-dependency (Lee \& Park, 2018), and immersion tendency (Kim \& Hwang, 2017). One study (Hutton et al., 2020) only reported 
whether a child had access to their own mobile device. Most studies $(N=20 ; 77 \%)$ reported use of both smartphones and tablets, while four included only smartphones (Cho \& Lee, 2017; Kim \& Hwang, 2017; Lee et al., 2015; Lee \& Park, 2018), and two included only tablets (Nathanson \& Beyens, 2018b; Neumann, 2014).

Only six studies $(23 \%)$ examined the nature of a child's smartphone or tablet use (Cho \& Lee, 2017; Kotrla Topić et al., 2020; Levine et al., 2019; Lin et al., 2020; Neumann, 2014; Taylor et al., 2017). These studies generally found that smartphones and tablets were most commonly used for non-educational purposes including watching videos (Cho \& Lee, 2017; Levine et al., 2019), entertainment (Kotrla Topić et al., 2020; Taylor et al., 2017) and gaming (Neumann, 2014). Sixty percent of primary caregivers surveyed in Lin et al. (2020) reported providing devices to young children to sooth them, while $40 \%$ of parents in Cho and Lee (2017) reported providing the device to amuse the child. In contrast, approximately $22 \%$ (Lin et al., 2020), 23\% (Levine et al., 2019) and 55\% (Neumann, 2014) of the respective samples in these studies reported that smartphones and tablets were used for educational purposes.

Psychosocial factors were generally measured through validated parent-reported instruments $(N=13)$, with the additional behavioral assessment of self-regulation in Lawrence et al. (2020) and a preschool teacher-reported assessment of child social skills in Gülay Ogelman et al. (2016). Child behavior-based questionnaires such as the Child Behavior Checklist (Achenbach \& Rescorla, 2000) and the Strengths and Difficulties Questionnaire (Goodman, 1997) were commonly used. Seven studies measuring cognitive and language factors used measures administered directly to the child by clinicians or researchers (Borajy et al., 2019; Hutton et al., 2020; Jusienė et al., 2020; Kotrla Topić et al., 2020; McNeill et al., 2019; Moon et al., 2019; Neumann, 2014). Child sleep-related factors were all reported by parents, with five studies employing validated questionnaires (Beyens \& Nathanson, 2019; Cheung et al., 2017; Nathanson \& Beyens, 2018a, 2018b; Zhu et al., 2020).

\section{Meta-Analysis and Research Synthesis}

Summaries of key findings for each study are presented for psychosocial factors (Table 1), cognitive factors (Table 2) and sleep (Table 3). The overall patterns of findings for each factor are presented in Figure 2, and a high-level summary of evidence is presented in Table 4.

Upon inspection of the available data, a meta-analysis was conducted on various subsets of factors, based on three levels of aggregation. This included associations of young children's 
amount of device use (i.e., duration or frequency of use, excluding parental perceptions of problematic use) with (a) all child factors aggregated, (b) psychosocial, cognitive, and sleep domains separately, and (c) more nuanced factors (i.e., self-regulation, language, executive functioning) within the domains where there were 3 or more studies available, as per recommendations by Borenstein et al. (2009). Table 5 presents the results of the meta-analysis (see Supplement S6 for forest plots). Overall, there was a weak negative correlation (16 studies, 26 effect sizes, $r=-.08, p=.001,95 \%$ CI [-.13, -.03], see Figure 3) between amount of use of smartphones and tablets and overall child-specific factors. Supplementary moderation analyses demonstrated that study quality and time period of publication were not significant moderators of this association (see Table S8 for further information). When an additional RVE model was run on the association between amount of smartphone and tablet use and overall child-specific factors, the pooled estimate remained statistically significant $(r=-.08, p=.017,95 \% \mathrm{CI}[-.15,-$ $.02])$. Finally, we conducted a separate meta-analysis focusing on parental perceptions of problematic smartphone or tablet use by young children, which showed a much stronger negative correlation with overall child-specific factors $(k=10, r=-.31, p=.001,95 \%$ CI [-.49, -.12], see Figure 4).

Examination of the heterogeneity of effect sizes suggest that most relationships showed moderate heterogeneity (see Table 5). An exception was seen for the association between overall child factors and parental perceptions of problematic use $\left(\tau=0.26 ; I^{2}=86.26 \% ; p<.0001\right)$ and the association with self-regulation $\left(\tau=0.15 ; I^{2}=86.44 \% ; p<.0001\right)$ which showed more substantial variation. Funnel plots and Egger regression test for asymmetry indicated statistically significant publication bias only for the analysis of association between parental perceptions of problematic use and overall factors $(\mathrm{z}=3.42, p<.001$; see Supplement S7 for further information). A description of meta-analytic findings with illustrative study methodological details are presented below.

\section{Psychosocial Factors}

The meta-analytic correlation between psychosocial factors and device use was nonsignificant $(k=12, r=-.07, p=.115,95 \% \mathrm{CI}[-.15, .02])$. In relation to amount of use (e.g., average duration) and problematic (e.g., addiction proneness) smartphone and tablet use in young children, self-regulation, externalizing, and internalizing behavior were the most commonly studied psychosocial factors, while interpersonal social skills (or prosocial behaviors) 
received limited attention. Most studies (9/12) analyzing the association of device use and psychosocial factors adjusted for other variables including child age, parental occupation, parental education, and family income. Collectively, children tended to spend more time on smartphones and tablets when they were older (Lawrence et al., 2020; Levine et al., 2019; McDaniel \& Radesky, 2020) and had parents who were less educated and used devices more (Levine et al., 2019). Studies that examined gender as a covariate found no differences between boys and girls in their amount of use of smartphones and tablets (McDaniel \& Radesky, 2020; Poulain et al., 2018).

Of the more nuanced psychosocial factors, only self-regulation had sufficient studies to conduct a meta-analysis. Externalizing and internalizing behavior, emotional factors, and social skills did not contain sufficient comparable effect sizes (less than three relevant effect sizes available for each variable in relation to amount of use) to conduct a meta-analysis. Specifically, the variation in measures of device use (i.e., amount of use vs. perceptions of problematic use), study designs and analyses (correlations and linear regressions vs. mean differences vs. logistic regressions) prevented the use of a meta-analysis for these psychosocial factors. Nevertheless, we present a summary of the systematic review findings of methodological details including study designs, covariates, and types of analyses used for these factors.

\section{Self-regulation}

The meta-analytic correlation between self-regulation and amount of device use (i.e., excluding parental perceptions of problematic device use) was close to zero and non-significant $(k=5, r=-.03, p=.65,95 \%$ CI $[-.18, .11])$. Five studies examined device use and selfregulation. In two studies, regression analyses were used to model device use as a predictor of self-regulation (Lawrence et al., 2020; Nathanson \& Beyens, 2018b), while the remaining three studies reversed the direction, modelling self-regulation as a predictor of device use (Kim \& Hwang, 2017; Lee \& Park, 2018; Levine et al., 2019). Additionally, self-regulation assessed as a facet of child temperament was included as a covariate in van den Heuvel et al. (2019) when examining the association between amount of device use and expressive language.

\section{Externalizing behavior}

Smartphone and tablet use was tested as a predictor of externalizing behavior (e.g., aggression or hyperactivity) cross-sectionally in two of six studies that examined the association between device use and child behavior (Cho \& Lee, 2017; Lin et al., 2020). In two longitudinal 
studies, externalizing behavior at baseline (McDaniel \& Radesky, 2020; Poulain et al., 2018), 6months follow-up (McDaniel \& Radesky, 2020), and 12-months follow-up (Poulain et al., 2018) were studied as both a predictor and outcome of device use to examine a possible reciprocal relationship between smartphone and/or tablet use and child behavior. A variety of analyses were used among the studies that assessed associations between device use and child behavior. Odds ratios of increased risk of behavioral problems between users and non-users of smartphones (Poulain et al., 2018), mean differences in behavioral problems between non-, low dose- and high-dose users of apps (McNeill et al., 2019) were reported in addition to linear relationships of continuous variables of device use and behavior scores (Cho \& Lee, 2017; Lee et al., 2015; Lin et al., 2020; McDaniel \& Radesky, 2020). Of the various covariates studied, significant mediating effects of parenting stress on the longitudinal association of externalizing behavior predicting tablet use at 6 months follow-up in young children is noteworthy (McDaniel \& Radesky, 2020). Interestingly, use of traditional devices (i.e., television), especially for program viewing, was found to be associated with increased externalizing behavior whereas use of smartphone and tablet-based media was not (McNeill et al., 2019).

\section{Emotional factors}

Of the five studies that investigated child emotional factors, three measured amount of device usage (Lin et al., 2020; McNeill et al., 2019; Poulain et al., 2018) while the other two measured parental perceptions of problematic use (Cho \& Lee, 2017; Lee et al., 2015). Two of the five studies were longitudinal (McNeill et al., 2019; Poulain et al., 2018). Similar to externalizing behavior, a variety of covariates were adjusted for in the regressions to assess associations between device use and emotional factors. Child and parent demographic characteristics such as age and gender were common covariates used across the studies (Cho \& Lee, 2017; Lin et al., 2020; McDaniel \& Radesky, 2020; McNeill et al., 2019; Poulain et al., 2018), while more specific factors such as parent education (Lin et al., 2020; McDaniel \& Radesky, 2020), socio-economic status (SES; McNeill et al., 2019; Poulain et al., 2018) and only child status (Lin et al., 2020) were also adjusted for. While studies including McNeill et al. (2019) and Poulain et al. (2018) attempted to use a more representative sampling approach through pre-school clustering and/or adjusting for SES, they note that, overall, participants were typically of higher SES. 


\section{Social development}

Cross-sectional associations between smartphone and tablet use and interpersonal social skills were explored in only two of the reviewed studies, both in preschool children (Gülay Ogelman et al., 2016; Moon et al., 2019). Neither of the studies adjusted their analyses for any covariates, however, Moon et al. (2019) performed separate correlational analyses for each age category ( 3 years vs. 4 years vs. 5 years) to account for the dynamic developmental differences across these young ages.

\section{Cognitive Factors}

There was no significant meta-analytic correlation between device use and cognitive factors $(k=10, r=-.07, p=.14,95 \%$ CI $[-.16, .02])$. Overall, half $(5 / 10)$ of the studies in the cognitive domain reported correlations as well as regression analyses statistically controlling for other factors including child and parent characteristics (Jusienè et al., 2020; Kotrla Topić et al., 2020; Lin et al., 2020; Taylor et al., 2017; van den Heuvel et al., 2019). Language and speech development were the most commonly examined variables in relation to smartphone and tablet use in these populations. Cognitive and language outcomes such as emergent literacy and executive functioning in relation to smartphone and tablet use were only studied in preschool children.

\section{Language and speech development}

The meta-analytic correlation between device use and language development was nonsignificant, $r=-.09, p=.09(k=9,95 \% \mathrm{CI}[-.20, .01])$. Two cross-sectional studies investigated smartphone and tablet use in relation to expressive and receptive language development (Lin et al., 2020) and expressive speech delay (van den Heuvel et al., 2019) in toddlers and preschool children (Moon et al., 2019). Three studies with relatively small samples of 69 (Hutton et al., 2020), 97 (Kotrla Topić et al., 2020) and 109 (Neumann, 2014) preschool children explored smartphone and tablet use with regards to emergent literacy. Interestingly, relationships of device use with literacy measures were no longer significant in two studies, once quality of home literacy environment (Kotrla Topić et al., 2020), and child's age (Neumann, 2014) were included as covariates. Unsurprisingly, children who were older (Neumann, 2014), were not the only child (Lin et al., 2020), who had more educated parents, and who spent more time engaged in interactive home reading (Kotrla Topić et al., 2020; Taylor et al., 2017) had more developed language and literacy levels. 


\section{Executive function and other cognitive factors}

The meta-analytic correlation between device use and executive function was nonsignificant $(k=5, r=-.09, p=.14,95 \%$ CI $[-.22, .05])$. The device use variables varied across four studies that explored the association with executive functioning related cognitive skills. While amount of overall smartphone and tablet usage was the more common approach (Jusiene et al., 2020; Moon et al., 2019), McNeill et al. (2019) focused on app usage specifically, and Hutton et al. (2020) studied the association with respect to child access to own device. Given the developmental sensitivity of cognitive skills during the preschool period, child age was considered an important factor to be accounted for in a majority (3/4) of these studies (Jusienè et al., 2020; McNeill et al., 2019; Moon et al., 2019). Correlational analyses was the most common statistical approach (Hutton et al., 2020; Jusienè et al., 2020; Moon et al., 2019), however, Jusienè et al. (2020) and McNeill et al. (2019) conducted multiple regression analyses predicting executive functioning related cognitive factors (e.g., working memory, inhibitory control) from device use, controlling for various demographic characteristics such as parent education.

\section{Sleep}

Overall, the meta-analysis of four studies found a significant negative correlation of $r=$ $.15, p<.001[95 \% \mathrm{CI}=-.22,-.08]$ between amount of device use and measures of child sleep outcomes. In addition to sleep duration (Cheung et al., 2017; Chindamo et al., 2019; Lan et al., 2020; Nathanson \& Beyens, 2018a, 2018b), a range of sleep quality indicators were studied in relation to daily and evening smartphone and tablet use, including bedtime resistance (Nathanson \& Beyens, 2018a, 2018b), night-time awakenings (Cheung et al., 2017), sleep onset latency (Cheung et al., 2017; Chindamo et al., 2019), sleep consolidation (i.e., less organization of sleep patterns due to less accrual of sleep over night; Beyens \& Nathanson, 2019), and risk of sleep disorder (Zhu et al., 2020). Notably, relatively large samples of 715 (Cheung et al., 2017) and 1117 (Chindamo et al., 2019) toddlers, as well as 2278 (Zhu et al., 2020) and 2903 (Lan et al., 2020) preschoolers, were studied to explore these associations cross-sectionally. Child demographic characteristics (i.e., age, gender), parental education levels, and SES-related variables were commonly studied covariates for the relationships between smartphone/ tablet use and sleep (Cheung et al., 2017; Chindamo et al., 2019; Lan et al., 2020; Nathanson \& Beyens, 2018a, 2018b; Zhu et al., 2020). Bedtime routine (Chindamo et al., 2019) and child's levels of daily activities (e.g., physical activity; Lan et al., 2020) were less commonly considered. 
Traditional device use, especially television exposure was accounted for in all studies that examined sleep in relation to device use. Interestingly, Zhu et al. (2020) found a stronger negative association between TV time and sleep compared to mobile screens, which is contrary to findings of Lan et al. (2020).

\section{Discussion}

The current study provides the first systematic review and meta-analysis of the associations of smartphone and tablet use with psychosocial, cognitive, and sleep-related factors in young children. While the meta-analysis provided an overall synthesis of the evidence of associations, the systematic review enabled an in-depth understanding of the methodology, potential covariates, and other noteworthy aspects of the included studies which helped to understand variations in study findings. Notably, the review shows that the study of early childhood smartphone and tablet use is an emerging area of empirical interest with the numbers of articles published each year increasing since 2014. Several important findings emerged. First, increased early childhood smartphone and tablet use was correlated, albeit weakly, with poorer overall child-specific developmental factors (i.e., aggregate of psychosocial, cognitive and sleep domains). Second, less conclusive evidence was present for the associations of smartphone and tablet use with psychosocial and cognitive factors in young children. Finally, greater use of smartphones and tablets was associated with poorer sleep outcomes in young children.

\section{Overall Child-Specific Factors}

The meta-analytic results provided initial evidence that greater smartphone and tablet use was associated with poorer aggregated child-specific proximal factors in early childhood.

Nonetheless, the correlations were quite small, and these modest associations were significant for only the overall aggregate and the sleep domain. Additionally, the meta-analysis was based on cross-sectional correlations, limiting the ability to draw inferences about causal relationships. As theorized by Domoff et al. (2020), simplistic correlational studies do not adequately capture the risk factors (e.g., distal influences through home environment and digital environment design; proximal influence from parents and peers) that may cause problematic media use in a child, in addition to child-specific factors. Thus, while the findings are consistent with the contention that smartphone and tablet use may displace developmentally healthy traditional activities such as play, reading, sleep, and physical activity in young children (AAP Council on Communications and Media, 2016), they are also consistent with other causal explanations. It would be helpful to 
see study designs, such as randomized controlled trials, used more frequently to facilitate rigorous investigation of potential causality between distal and proximal influences on early childhood screen use and development.

Furthermore, meta-analytic evidence showed that parental perceptions of problematic childhood screen use were more strongly associated with poorer overall child-specific factors than with the general amount of child device use. This is not particularly surprising as parents who perceive their child's use to be problematic may be more likely to also perceive problems with their child's behavior and well-being.

Despite the inclusion of parental observations as usage measures in the early childhoodscreen use literature, the inclusion of parenting practices surrounding childhood smartphone and tablet use is far less common. Only $4(15 \%)$ of the included studies accounted for parenting related variables in their statistical models. The Domoff et al. (2020) framework incorporates parenting practices and beliefs as variables that exert important proximal influences on childhood device use. Parental factors, such as attitudes towards technology, parenting styles, and parenting efficacy, are also likely to guide parental practices in managing children's screen use (Sanders et al., 2016). Accordingly, parents vary in their reasons for providing devices to their children. Reasons can include education, amusement, or convenience (Radesky et al., 2015), and parenting styles and attitudes are likely to inform the technology-related screen-time management strategies used by parents (e.g., level of intervention, level of facilitated exposure and timesetting). Having information about parental beliefs and attitudes, along with their use of management strategies, can add clarity to the context of screen use by young children. That is, to what extent does a child engage with a device based on their own initiative versus a parent facilitating use of the device. Given a young child's limited autonomy, incorporating parental perceptions, practices, and challenges in future research on associations of young children's use of smartphones and tablets, is of primary importance.

\section{Psychosocial and Cognitive Factors}

The meta-analytic results in the psychosocial and cognitive domains were not significant, aligning with the high variation in findings as evident through the systematic review. This differs from past reviews of overall screen time (combination of traditional and contemporary devices) (e.g., Duch et al., 2013; Radesky \& Christakis, 2016) which found negative relationships for amount of screen time with psychosocial and cognitive development in early childhood. There 
are two plausible explanations for the non-significant results. First, the variation is likely to be partially attributable to the heterogeneity in study designs, and varying measurements of screen use and child psychosocial or cognitive factors (see the forthcoming section 'Recommendations for Future Research' for further details). Second, the non-significant association with smartphones and tablets compared to traditional television usage may be due to the inherent differences in the amount and types of usage each device offers. Past research has typically relied on generic, free-to-air television programming where the amount of high-quality educational content is limited. In contrast, smartphone and tablet content is typically curated for the individual child and is unlimited in terms of access to interactive, educational, and social applications. This warrants more in-depth understanding of the nature of use of smartphones and tablets when examining its relationships with psychosocial or cognitive factors, based on how the child uses the device.

Despite the many other variables that were examined in studies in this review (as covariates), relevant information on the multiple levels of influence which drive child media use as proposed by the Domoff et al. (2020) model were rarely provided. Specifically, proximal influences such as parenting stress and practices, along with parents' own use, and distal influences including household dynamics, socio-economic status, and digital environmental design were often overlooked. These influences may further clarify the varying conditions under which use of mobile screens may be beneficial or detrimental to child's well-being and development. While it may not be feasible to consider all of these factors in a single study, it is important to acknowledge their potential interactions and to assess their influence through longitudinal cohort studies. The early childhood screen time literature would benefit from longitudinal studies assessing the interactional influences these factors may have, while assessing the continuous changes which occur within these factors over time (e.g., changing technology, child's developmental changes).

\section{Psychosocial factors}

Of the psychosocial factors, self-regulation received the most attention and was the only psychosocial factor with enough relevant primary studies for a meta-analysis. The meta-analytic evidence did not demonstrate a significant association between amount of use and selfregulation. The pooled effect size does not reflect the negative associations between problematic use of smartphones and self-regulation in adolescents and adults (Berger et al., 2018; Kim et al., 
2016; Yang et al., 2019). The non-significant result may be understood in terms of the way that child screen usage is conceptualized within studies of child self-regulation. The present metaanalysis utilized only data that represented actual amount of child smartphone/ tablet usage in early childhood, whereas past self-regulation literature in relation to screen use in older populations predominantly relies on measures of parental or self-evaluations of problematic smartphone or tablet use. Thus, there is a clear need to delineate raw amount of use from perceptions of problematic use in future research, to more clearly to understand any differential effects on child well-being and development.

\section{Cognitive factors}

The sub-group analysis of executive functioning-related cognitive factors with use of smartphones and tablets in young children yielded similar non-significant results. The nonsignificant relationship could suggest a more pronounced contribution of environmental influences (e.g., the home literacy environment), biological influences (e.g., genetics), or parental factors (e.g., level of education and literacy beliefs) to young children's early cognitive and language development (Burgess et al., 2002; Weigel et al., 2006). However, the paucity of longitudinal research and the limited number of cognitive factors tested in the very few existing studies, limits drawing any definitive conclusions about the effects of mobile screens on executive function and cognitive development in young children.

The meta-analysis obtained a small negative association between device use and language-related variables, but this was non-significant, consistent with the mix of significant and non-significant associations in the primary studies that examined language, literacy, and speech development. More insight into types of use (i.e., passive vs. interactive use) of smartphones and tablets would be required to fully elucidate this relationship. Theory and the broader screen time literature suggests that high levels of solo passive device use, as opposed to co-use with parents or siblings, may be more problematic for language development where it displaces social interactions and other activities that foster language skills. For instance, Madigan et al. (2020) found in their review that language skills were negatively associated with overall screen time (i.e., a combination of traditional and new media), but positively associated with coviewing and viewing higher quality educational programs. Given that language and literacy apps are now highly prevalent among families of preschoolers to promote emergent literacy in the digital world (Neumann \& Neumann, 2017), testing for associations of language skills with 
higher quality apps and content is warranted. Thus, longitudinal studies should aim to include more experimental investigations of the use of language and literacy apps to examine their shortand long-term effects on language and literacy-related outcomes in young children. The distal influence of digital environmental design (Domoff et al., 2020) is also of relevance in this context, given that persuasive design features (e.g., continuous rewards, auto-play, reduced mental effort) may divert a child's attention away from language or literacy learning content (Barr et al., 2018; Hirsh-Pasek et al., 2015; Meyer et al., 2021). In addition to experimental studies, intervention studies which implement additional parental controls and minimize the persuasive features of child-focused apps could aim to evaluate their effects on children's cognitive and language outcomes.

\section{Sleep-Related Factors}

Overall, the systematic review and meta-analysis indicated that smartphone and tablet use had a significant but weak relationship with less sleep and poorer sleep quality (i.e., increased bedtime resistance and delayed sleep onset) in young children. It is also important to acknowledge that the amount of sleep that most children need is much less at the end of early childhood (i.e., age 6) than at the beginning (i.e., age 1). Given that device use increases with age, it is particularly important for studies to control for age-related changes. Accounting for socio-cultural factors with regards to timing of evening activities (e.g., dinner time) and bedtime routines or practices (e.g., co-sleeping, reading before sleep, liquids before sleep) is of further importance, given their potential moderating effect on the relationship between screen use and sleep in young children.

Nonetheless, the present study findings are consistent with previous reviews conducted in early childhood populations, which have reported negative associations between sedentary screen media use (i.e., television viewing and computer use) and sleep duration or healthy sleeping routines (Janssen et al., 2020; Zhang et al., 2021). The blue light emissions from smartphones and tablets, which are typically held much closer to the face than traditional media (Twenge et al., 2019), may help to explain the association. Blue light is known to interfere with circadian rhythms and sleep cycles, and disrupted circadian rhythms can lead to bedtime resistance, delayed sleep onset, and reduced sleep in children and adolescents (see Cain \& Gradisar, 2010 for a review). Compared to traditional media such as television, the portability of smartphones and tablets means that they can be used in bed, thereby increasing the likelihood of 
disrupted or displaced sleep routines (Twenge et al., 2019). Previous research in older child and adolescent populations has found that inadequate sleep quantity and poorer sleep quality is associated with greater smartphone use (see Carter et al., 2016 for a review). Accordingly, greater smartphone and tablet use, especially at night-time, may have adverse implications for sleep in toddlers and preschool children due to one or more of these reasons.

Adequate and good-quality sleep is also a well-established factor in healthy child development, especially in key psychosocial and cognitive domains (see El-Sheikh \& Sadeh, 2015 for a review). Parent et al. (2016) and Wu et al. (2017) found that compromised sleep quality that resulted from smartphone or tablet use may contribute to increased irritability and externalizing behavior in young children. Similarly, sleep quality was a mediator in Nathanson and Beyens (2018b), where evening tablet use was related to delayed sleep onset, greater bedtime resistance, and overall, poorer sleep quality, which in turn predicted poorer effortful control. This highlights the need to further investigate the extent to which sleep mediates any effect of early childhood device use on behavioral regulation, especially over time.

\section{Recommendations for Future Research}

We identify several methodological issues and gaps in the literature, specifically in relation to (a) conceptualization and measurement of smartphone and tablet use, (b) measurement of children's development, and (c) consistency in age brackets of early childhood samples. Addressing these issues in future research would allow for better synthesis of research findings.

\section{Conceptualization and Measurement of Smartphone and Tablet Use in Early Childhood}

First, smartphone and tablet use should be conceptualized as a multifaceted variable. In addition to the amount of time and frequency of device use, researchers should also seek to measure; (a) type of use (e.g. whether it is passive or interactive, whether it is solitary or involves co-use), (b) the content (e.g., educational, social, or recreational), (c) the timing of the use (e.g., around bedtime or during the day), and (d) the reasons for use (e.g., entertainment, boredom, distress, learning). It is also important to consider the child's overall history of device use (i.e., age at first regular device use and time from child's first regular use). Further, it is important to understand the degree to which smartphone and tablet use is supplanting other forms of screen time, such as watching television, and how multi-screen use is related to developmental factors.

Second, future research should seek to supplement parent reports of smartphone and 
tablet use with objective measures (e.g., Radesky et al., 2020). Despite the popularity and convenience of parent reports, they are imperfect and subject to problems with recall and socially desirable responding. For instance, a recent meta-analysis of mostly young adults suggests that people are only moderately accurate at estimating their own smartphone use (Parry et al., 2021). That said, the meta-analysis did pool measures of problematic usage and estimates of amount of use; a more recent large sample study of the general adult population with greater variance in objective usage suggested that self-rated estimates were somewhat more accurate (Horwood et al., 2021). In summary, people appear to be able to provide rough estimates of use, but they are imprecise. Obtaining objective measures of device use would also enable more fine-grained analyses of the multifaceted nature of smartphone use.

Third, considerable care is required when interpreting findings based on measures of perceived problematic device use. While most studies have focused on amount of use, other studies have formulated various definitions of excessive or problematic use. Heterogeneity of operationalizations makes comparison of problematic device use in early childhood difficult. Furthermore, the use of the word 'addiction' implies a clinically diagnosable level of any behavior and seems to over-reach for the purposes of assessing excessive screen use in young children. We propose a more consistent and tempered term, 'problematic mobile screen use', in young children to better understand the phenomenon. But considerable empirical work is required to operationalize 'problematic use'.

\section{Measurement of Children's Development}

Another challenge for research synthesis is the variation in type of measures used for the same or similar child developmental factors. Similar to measurement of smartphone/ tablet use, the sole reliance on parent and/or teacher reports for assessment of child development poses the risk of various inherent biases, which potentially may be compounded in instances where there is a common rater for both child's smartphone/ tablet use and child factors. On the other hand, several studies in the review employed validated or clinically administered measures for measurement of developmental constructs. Accordingly, this variation in the type of measure used is also a plausible factor which may have contributed to some of the heterogeneity observed in study findings in our review. To overcome this limitation in future research, we propose the consistent use of norm-referenced standardized measures which may better tap into the underlying developmental constructs of primary interest. In part, this may also resolve any issues 
with inconsistency in terminology and definitions of developmental constructs (e.g., 'externalizing behavior' also termed 'aggressive behavior', 'behavioral problems or difficulties' and 'externalizing symptoms') that are used across research in the screen time field.

\section{Determination of Age Groups for Study Samples}

While the review attempted to discretely outline findings for the two different developmental groups of toddler and preschool children, there was substantial variation in how researchers defined toddler and preschooler age ranges. The inconsistency could be a function of the differing global educational systems. For example, in Australia and the UK, pre-school age typically ends at 5 years old when primary (elementary) school commences, however children typically start primary school later at age 6 (e.g., US, China, India) or 7 (e.g., Sweden, South Africa) in other parts of the world. Future research should aim to account for the importance of developmental stages when determining prospective samples and analyses in future studies. Increasing levels of data sharing in future publications is an open science practice that would enable researchers to conduct appropriate statistical analyses by filtering or accounting for age.

\section{Practical Recommendations}

Despite the wealth of evidence which suggests that harms of longer and more frequent use of smartphones and tablets may outweigh the benefits of such use, there is a general lack of reporting of specific dose-response relationships that can determine a threshold for use which may pose negative implications. Therefore, at this stage, it may be useful to be guided by the American Academy of Pediatrics 2016 statement (AAP Council on Communications and Media, 2016). The AAP recommendations state that children under 18 to 24 months of age should not engage in any screen time (with the exception of parent-mediated video chatting) while those aged 2 to 5 years should ideally consume only high-quality screen time for a maximum of an hour per day. These AAP recommendations are illustrative of the international guidelines targeted for worldwide screen use in early childhood, as they align with the physical activity, sedentary screen time, and sleep guidelines (World Health Organization, 2019) which also recommend that children aged less than 2 years have no sedentary screen time and those aged 2 to 5 years have no more than one hour per day.

While the evidence base is only just emerging, we offer the following initial recommendations for early childhood educators and clinicians. First, the potential negative associations between smartphone and tablet use and child-specific factors outline the importance 
of assisting and guiding parents to identify alternative non-screen-based strategies to use in instances where device use may otherwise impede development of a child's natural regulatory mechanisms (e.g., to soothe or occupy a child). Second, the AAP screen time recommendations (AAP Council on Communications and Media, 2016) around avoiding device use within one hour of bedtime should be emphasized to families, to highlight the importance of the timing of device use and potential implications on young children's sleep. Third, it is important to help parents consider the content and context of smartphone and tablet use in addition to time spent on these devices, i.e., is the content developmentally appropriate and easy to switch off? As outlined in the Zero to Three's recent research report (Barr et al., 2018), the 3C's: Child (i.e., unique, individual child characteristics), Content (i.e., the quality and meaningfulness of the media content) and Context (i.e., the setting in which child uses device; alone or with parents/ siblings) can be useful as a simple rule-of-thumb for parents when choosing appropriate screen media on mobile devices for their child. Finally, families should be advised to be cognizant of the unique features of smartphones and tablets compared to traditional media (such as television), which includes increased tendency for solitary use, enticing touch-screen interface (Haughton et al., 2015) and exposure to high amounts of advertising via internet connectivity (Domoff et al., 2020). Thus, a note of caution is warranted for decisions surrounding provision of these devices at increasingly younger ages in early childhood. Families could be advised to avoid introducing technology early, as children are very capable of grasping the necessary skills as they engage in use of these devices in learning contexts (AAP Council on Communications and Media, 2016).

\section{Strengths and Limitations}

There are several strengths and limitations of the review that should be acknowledged. A major strength of the review was the protocol which employed a broad and verified search strategy to incorporate a widespread range of child-specific proximal factors in psychosocial, cognitive, and language domains, and further including sleep-related factors which have a central influence on young children's development. Screening, data extraction and quality assessment were carried out independently by two reviewers maintaining a high inter-rater reliability. The PRISMA checklist was followed throughout the review and in the reporting (see Supplement S9). Nevertheless, several limitations should be noted. First, the main limitation is that the research literature is only just emerging. As such, more research is needed for more definitive 
and nuanced conclusions. Relatedly, the high degree of heterogeneity in measures combined with the relatively small number of studies, limited the ability to meta-analytically examine more specific measures. Finally, as predominantly published findings were included in both the meta-

analysis and systematic review, the possibility of publication bias could not be completely ruled out.

\section{Conclusion}

It is promising to see a growing number of research studies investigating intra- and interpersonal child-specific psychosocial, cognitive, and sleep factors in early childhood smartphone and tablet use. Although it is difficult to draw robust inferences about the directionality or dosage effects, there was some evidence that increased amount of smartphone and tablet use was associated with slightly poorer measures of child-specific factors, particularly in relation to sleep. Self-regulation, internalizing and externalizing behavior, social skills, cognitive, and language development remain areas to be further investigated. Future research should aim to conduct methodologically rigorous studies examining longitudinal associations between smartphone and tablet use and psychosocial, cognitive, and sleep domains of child development. The metaanalytic associations that were investigated in this review were correlational, however, in reality, early childhood screen use is likely to be far more nuanced. Therefore, future research should also seek to model the effect of additional factors including parenting practices and beliefs, the household environment, and the digital environment design on young children's smartphone and tablet use. The multiple aspects of smartphone and tablet use, i.e., duration, frequency, content, context, and history of use, are important to be considered individually as well as in combination, to further understand the developmental implications. Consequently, this would better inform policy-making and general recommendations for parents, educators, clinicians, and stakeholders in the digital media industry. Deeper insights into manifestation of problematic mobile screen use in early childhood would also enable effective early intervention of such problematic use. 


\section{References}

AAP Council on Communications and Media. (2016). Media and Young Minds. Pediatrics, 138(5), e20162591. https://doi.org/10.1542/peds.2016-2591

Achenbach, T. M., \& Rescorla, L. A. (2000). Child behavior checklist for ages 1 1/2-5. ASEBA. University of Vermont.

Adelantado-Renau, M., Moliner-Urdiales, D., Cavero-Redondo, I., Beltran-Valls, M. R., Martínez-Vizcaíno, V., \& Álvarez-Bueno, C. (2019). Association between screen media use and academic performance among children and adolescents: a systematic review and meta-analysis. JAMA Pediatrics, 173(11), 1058-1067.

Anders, T. F. (2004). Sleep-Wake states and problems and child psychosocial development. Tremblay RE. Encyclopedia on early childhood development. Montreal (CAN): Centre of Excellence for Early Childhood Development, 1-6.

Barr, R., McClure, E., \& Parlakian, R. (2018). What the research says about the impact of media on children aged 0-3 years old. ZERO TO THREE, Washington DC.

Bedford, R., Saez de Urabain, I. R., Cheung, C. H., Karmiloff-Smith, A., \& Smith, T. J. (2016). Toddlers' fine motor milestone achievement is associated with early touchscreen scrolling. Frontiers in psychology, 7, 1108.

Berger, S., Wyss, A. M., \& Knoch, D. (2018). Low self-control capacity is associated with immediate responses to smartphone signals [Report]. Computers in Human Behavior. https://doi.org/10.1016/j.chb.2018.04.031

Beyens, I., \& Nathanson, A. I. (2019, May). Electronic Media Use and Sleep Among Preschoolers: Evidence for Time-Shifted and Less Consolidated Sleep. Health Commun, 34(5), 537-544. https://doi.org/10.1080/10410236.2017.1422102 
Borajy, S., Albkhari, D., Turkistani, H., Altuwairiqi, R., Aboalshamat, K., Altaib, T., \& Almehman, W. (2019). Relationship of electronic device usage with obesity and speech delay in children. Family Medicine \& Primary Care Review, 21(2), 93-97. https://doi.org/10.5114/fmpcr.2019.84542

Borenstein, M., Hedges, L. V., Higgins, J. P., \& Rothstein, H. R. (2009). Introduction to metaanalysis. John Wiley \& Sons.

Bronfenbrenner, U., \& Morris, P. A. (2007). The bioecological model of human development. Handbook of child psychology, 1 .

Burdette, H. L., \& Whitaker, R. C. (2005). Resurrecting free play in young children: looking beyond fitness and fatness to attention, affiliation, and affect. Archives of pediatrics \& adolescent medicine, 159(1), 46-50.

Burgess, S. R., Hecht, S. A., \& Lonigan, C. J. (2002). Relations of the home literacy environment (HLE) to the development of reading - related abilities: A one - year longitudinal study. Reading Research Quarterly, 37(4), 408-426.

Cain, N., \& Gradisar, M. (2010). Electronic media use and sleep in school-aged children and adolescents: A review. Sleep medicine, 11(8), 735-742.

Cannoni, E., Scalisi, T. G., \& Giangrande, A. (2018). Indagine sui bambini di 5-6 anni che usano quotidianamente i dispositivi mobili in ambito familiare: Caratteristiche personali e contestuali e problematiche cognitive ed emotive. Rassegna di Psicologia.

Carr, A., Duff, H., \& Craddock, F. (2020). A systematic review of reviews of the outcome of severe neglect in underresourced childcare institutions. Trauma, Violence, \& Abuse, 21(3), 484-497. 
Carson, V., Hunter, S., Kuzik, N., Gray, C. E., Poitras, V. J., Chaput, J.-P., Saunders, T. J., Katzmarzyk, P. T., Okely, A. D., \& Connor Gorber, S. (2016). Systematic review of sedentary behaviour and health indicators in school-aged children and youth: an update. Applied Physiology, Nutrition, and Metabolism, 41(6), S240-S265.

Carter, B., Rees, P., Hale, L., Bhattacharjee, D., \& Paradkar, M. S. (2016). Association between portable screen-based media device access or use and sleep outcomes: a systematic review and meta-analysis. JAMA Pediatrics, 170(12), 1202-1208.

Cheung, C. H., Bedford, R., Saez De Urabain, I. R., Karmiloff-Smith, A., \& Smith, T. J. (2017, Apr 13). Daily touchscreen use in infants and toddlers is associated with reduced sleep and delayed sleep onset. Sci Rep, 7, 46104. https://doi.org/10.1038/srep46104

Chindamo, S., Buja, A., DeBattisti, E., Terraneo, A., Marini, E., Gomez Perez, L. J., Marconi, L., Baldo, V., Chiamenti, G., Doria, M., Ceschin, F., Malorgio, E., Tommasi, M., Sperotto, M., Buzzetti, R., \& Gallimberti, L. (2019, Apr). Sleep and new media usage in toddlers. Eur J Pediatr, 178(4), 483-490. https://doi.org/10.1007/s00431-019-03318-7

Chiong, C., \& Shuler, C. (2010). Learning: Is there an app for that. Investigations of young children's usage and learning with mobile devices and apps. New York: The Joan Ganz Cooney Center at Sesame Workshop,

Cho, K.-S., \& Lee, J.-M. (2017). Influence of smartphone addiction proneness of young children on problematic behaviors and emotional intelligence: Mediating self-assessment effects of parents using smartphones. Computers in Human Behavior, 66, 303-311. https://doi.org/10.1016/j.chb.2016.09.063

Domoff, S. E., Borgen, A. L., \& Radesky, J. S. (2020). Interactional theory of childhood problematic media use. Human Behavior and Emerging Technologies. 
Duch, H., Fisher, E. M., Ensari, I., \& Harrington, A. (2013). Screen time use in children under 3 years old: a systematic review of correlates. International journal of behavioral nutrition and physical activity, 10(1), 1-10.

El-Sheikh, M., \& Sadeh, A. (2015). I. Sleep and development: introduction to the monograph. Monographs of the society for research in child development, 80(1), 1-14.

Fisher, Z., \& Tipton, E. (2015). robumeta: An R-package for robust variance estimation in metaanalysis. arXiv preprint arXiv:1503.02220.

Fox, S. E., Levitt, P., \& Nelson III, C. A. (2010). How the timing and quality of early experiences influence the development of brain architecture. Child development, 81(1), $28-40$

Ginsburg, K. R. (2007). The importance of play in promoting healthy child development and maintaining strong parent-child bonds. Pediatrics, 119(1), 182-191.

Goodman, R. (1997). The Strengths and Difficulties Questionnaire: a research note. Journal of Child Psychology and Psychiatry, 38(5), 581-586.

Gülay Ogelman, H., Güngör, H., Körükçü, Ö., \& Erten Sarkaya, H. (2016). Examination of the relationship between technology use of 5-6 year-old children and their social skills and social status. Early Child Development and Care, 188(2), 168-182. https://doi.org/10.1080/03004430.2016.1208190

Haughton, C., Aiken, M., \& Cheevers, C. (2015). Cyber babies: The impact of emerging technology on the developing infant. Psychology, 5(9), 504-518.

Hedges, L. V., Tipton, E., \& Johnson, M. C. (2010). Robust variance estimation in meta regression with dependent effect size estimates. Research synthesis methods, 1(1), 39-65. 
Herodotou, C. (2018). Young children and tablets: A systematic review of effects on learning and development. Journal of Computer Assisted Learning, 34(1), 1-9.

[Record \#213 is using a reference type undefined in this output style.]

Hinkley, T., Teychenne, M., Downing, K. L., Ball, K., Salmon, J., \& Hesketh, K. D. (2014). Early childhood physical activity, sedentary behaviors and psychosocial well-being: a systematic review. Preventive medicine, 62, 182-192.

Hirsh-Pasek, K., Zosh, J. M., Golinkoff, R. M., Gray, J. H., Robb, M. B., \& Kaufman, J. (2015). Putting education in "educational" apps: Lessons from the science of learning. Psychological Science in the Public Interest, 16(1), 3-34.

Horwitz, S. M., Irwin, J. R., Briggs-Gowan, M. J., Heenan, J. M. B., Mendoza, J., \& Carter, A. S. (2003). Language delay in a community cohort of young children. Journal of the American Academy of Child \& Adolescent Psychiatry, 42(8), 932-940.

Horwood, S., Anglim, J., \& Mallawaarachchi, S. R. (2021). Problematic smartphone use in a large nationally representative sample: Age, reporting biases, and technology concerns. Computers in Human Behavior, 122, 106848.

Hoyniak, C. P., Bates, J. E., McQuillan, M. E., Staples, A. D., Petersen, I. T., Rudasill, K. M., \& Molfese, V. J. (2020). Sleep across early childhood: implications for internalizing and externalizing problems, socioemotional skills, and cognitive and academic abilities in preschool. Journal of Child Psychology and Psychiatry, 61(10), 1080-1091.

Huber, B., Tarasuik, J., Antoniou, M. N., Garrett, C., Bowe, S. J., Kaufman, J., \& Team, S. B. (2016). Young children's transfer of learning from a touchscreen device. Computers in Human Behavior, 56, 56-64. 
Huber, B., Yeates, M., Meyer, D., Fleckhammer, L., \& Kaufman, J. (2018). The effects of screen media content on young children's executive functioning. Journal of experimental child psychology, 170, 72-85.

Hutton, J. S., Huang, G., Sahay, R. D., DeWitt, T., \& Ittenbach, R. F. (2020, Jun). A novel, composite measure of screen-based media use in young children (ScreenQ) and associations with parenting practices and cognitive abilities. Pediatr Res, 87(7), 12111218. https://doi.org/10.1038/s41390-020-0765-1

Innovation, V. H. Covidence systematic review software www.covidence.org

Janssen, X., Martin, A., Hughes, A. R., Hill, C. M., Kotronoulas, G., \& Hesketh, K. R. (2020). Associations of screen time, sedentary time and physical activity with sleep in under $5 \mathrm{~s}$ : A systematic review and meta-analysis. Sleep medicine reviews, 49, 101226.

Janus, M., \& Offord, D. R. (2007). Development and psychometric properties of the Early Development Instrument (EDI): A measure of children's school readiness. Canadian Journal of Behavioural Science/Revue canadienne des sciences du comportement, 39(1), 1.

Jimenez, M. E., Wade, R., Lin, Y., Morrow, L. M., \& Reichman, N. E. (2016). Adverse experiences in early childhood and kindergarten outcomes. Pediatrics, 137(2), e20151839.

Jusienè, R., Rakickienė, L., Breidokienė, R., \& Laurinaitytė, I. (2020). Executive function and screen - based media use in preschool children. Infant and Child Development, 29(1). https://doi.org/10.1002/icd.2173 
Kabali, H. K., Irigoyen, M. M., Nunez-Davis, R., Budacki, J. G., Mohanty, S. H., Leister, K. P., \& Bonner, R. L. (2015). Exposure and use of mobile media devices by young children. Pediatrics, 136(6), 1044-1050.

Kaur, N., Gupta, M., Malhi, P., \& Grover, S. (2019). Screen time in under-five children. Indian pediatrics, 56(9), 773-788.

Kim, S.-H., \& Hwang, S.-O. (2017). Mediating Effects of Self-Regulation on the Relationship between Childhood Smart Device Immersion Tendency and Pro-Social Behavior. Family and Environment Research, 55(1), 1-12. https://doi.org/10.6115/fer.2017.001

Kim, Y., Jeong, J.-E., Cho, H., Jung, D.-J., Kwak, M., Rho, M. J., Yu, H., Kim, D.-J., \& Choi, I. Y. (2016). Personality factors predicting smartphone addiction predisposition: Behavioral inhibition and activation systems, impulsivity, and self-control. PloS one, 11(8), $\mathrm{e} 0159788$.

Kocevska, D., Rijlaarsdam, J., Ghassabian, A., Jaddoe, V. W., Franco, O. H., Verhulst, F. C., \& Tiemeier, H. (2017). Early childhood sleep patterns and cognitive development at age 6 years: the Generation R Study. Journal of pediatric psychology, 42(3), 260-268.

Kostyrka-Allchorne, K., Cooper, N. R., \& Simpson, A. (2017). The relationship between television exposure and children's cognition and behaviour: A systematic review. Developmental Review, 44, 19-58.

Kotrla Topić, M., Sakic Velic, M., \& Merkas, M. (2020, Jun). Tablet and Smartphone or a Book: The Struggle Between Digital Media and Literacy Environment in Homes of Croatian Preschool Children and Its Effect on Letter Recognition. Cyberpsychol Behav Soc Netw, 23(6), 412-417. https://doi.org/10.1089/cyber.2019.0482 
Lan, Q.-Y., Chan, K. C., Kwan, N. Y., Chan, N. Y., Wing, Y. K., Li, A. M., \& Au, C. T. (2020). Sleep duration in preschool children and impact of screen time. Sleep medicine, 76, 4854.

Lawrence, A. C., \& Choe, D. E. (2021). Mobile Media and Young Children's Cognitive Skills: A Review. Academic Pediatrics.

Lawrence, A. C., Narayan, M. S., \& Choe, D. E. (2020, Mar 30). Association of Young Children's Use of Mobile Devices With Their Self-regulation. JAMA Pediatr. https://doi.org/10.1001/jamapediatrics.2020.0129

LeBlanc, A. G., Spence, J. C., Carson, V., Connor Gorber, S., Dillman, C., Janssen, I., Kho, M. E., Stearns, J. A., Timmons, B. W., \& Tremblay, M. S. (2012). Systematic review of sedentary behaviour and health indicators in the early years (aged 0-4 years). Applied Physiology, Nutrition, and Metabolism, 37(4), 753-772.

[Record \#176 is using a reference type undefined in this output style.]

Lee, H.-J., Chae, S.-M., Bang, K.-S., \& Choi, H. (2015). Relationships Among Preschoolers' Smartphone Addiction Tendency, Their Problem Behaviors, and Parenting Efficacy of Their Mothers. Child Health Nursing Research, 21(2), 107-114. https://doi.org/10.4094/chnr.2015.21.2.107

Lee, M., \& Park, S. (2018). Factors associated with Smartphone Overdependency in Preschool Children. Child Health Nursing Research, 24(4), 383-392. https://doi.org/10.4094/chnr.2018.24.4.383

Levine, L. E., Waite, B. M., Bowman, L. L., \& Kachinsky, K. (2019). Mobile media use by infants and toddlers. Computers in Human Behavior, 94, 92-99. https://doi.org/10.1016/j.chb.2018.12.045 
Lillard, A. S., Lerner, M. D., Hopkins, E. J., Dore, R. A., Smith, E. D., \& Palmquist, C. M. (2013). The impact of pretend play on children's development: A review of the evidence. Psychological bulletin, 139(1), 1.

Lin, H. P., Chen, K. L., Chou, W., Yuan, K. S., Yen, S. Y., Chen, Y. S., \& Chow, J. C. (2020, Feb). Prolonged touch screen device usage is associated with emotional and behavioral problems, but not language delay, in toddlers. Infant Behav Dev, 58, 101424. https://doi.org/10.1016/j.infbeh.2020.101424

Madigan, S., Browne, D., Racine, N., Mori, C., \& Tough, S. (2019). Association between screen time and children's performance on a developmental screening test. JAMA Pediatrics, 173(3), 244-250.

Madigan, S., McArthur, B. A., Anhorn, C., Eirich, R., \& Christakis, D. A. (2020). Associations Between Screen Use and Child Language Skills: A Systematic Review and Metaanalysis. JAMA Pediatrics.

McCabe, P. C., \& Altamura, M. (2011). Empirically valid strategies to improve social and emotional competence of preschool children. Psychology in the Schools, 48(5), 513-540.

McDaniel, B. T., \& Radesky, J. S. (2020, Jun). Longitudinal Associations Between Early Childhood Externalizing Behavior, Parenting Stress, and Child Media Use. Cyberpsychol Behav Soc Netw, 23(6), 384-391. https://doi.org/10.1089/cyber.2019.0478

McNeill, J., Howard, S. J., Vella, S. A., \& Cliff, D. P. (2019). Longitudinal associations of electronic application use and media program viewing with cognitive and psychosocial development in preschoolers. Academic Pediatrics, 19(5), 520-528.

Meyer, M., Zosh, J. M., McLaren, C., Robb, M., McCaffery, H., Golinkoff, R. M., Hirsh-Pasek, K., \& Radesky, J. (2021). How educational are "educational” apps for young children? 
App store content analysis using the Four Pillars of Learning framework. Journal of Children and Media, 1-23.

Moher, D., Altman, D. G., Liberati, A., \& Tetzlaff, J. (2011). PRISMA statement. Epidemiology, $22(1), 128$.

Moon, J. H., Cho, S. Y., Lim, S. M., Roh, J. H., Koh, M. S., Kim, Y. J., \& Nam, E. (2019, May). Smart device usage in early childhood is differentially associated with fine motor and language development. Acta Paediatr, 108(5), 903-910. https://doi.org/10.1111/apa.14623

Nathanson, A. I., \& Beyens, I. (2018a, Mar-Apr). The Relation Between Use of Mobile Electronic Devices and Bedtime Resistance, Sleep Duration, and Daytime Sleepiness Among Preschoolers. Behav Sleep Med, 16(2), 202-219. https://doi.org/10.1080/15402002.2016.1188389

Nathanson, A. I., \& Beyens, I. (2018b, Mar). The role of sleep in the relation between young children's mobile media use and effortful control. Br J Dev Psychol, 36(1), 1-21. https://doi.org/10.1111/bjdp.12196

National Heart, L., and Blood Institute. (2014). Quality assessment tool for observational cohort and cross-sectional studies. Bethesda: National Institutes of Health, Department of Health and Human Services.

Neumann, M. M. (2014). An examination of touch screen tablets and emergent literacy in Australian pre-school children. Australian Journal of Education, 58(2), 109-122. https://doi.org/10.1177/0004944114523368

Neumann, M. M., \& Neumann, D. L. (2017). The use of touch-screen tablets at home and preschool to foster emergent literacy. Journal of Early Childhood Literacy, 17(2), 203-220. 
Parent, J., Sanders, W., \& Forehand, R. (2016). Youth screen time and behavioral health problems: The role of sleep duration and disturbances. Journal of developmental and behavioral pediatrics: JDBP, 37(4), 277.

Parry, D. A., Davidson, B. I., Sewall, C. J., Fisher, J. T., Mieczkowski, H., \& Quintana, D. S. (2021). A systematic review and meta-analysis of discrepancies between logged and selfreported digital media use. Nature Human Behaviour, 1-13.

Paudel, S., Jancey, J., Subedi, N., \& Leavy, J. (2017). Correlates of mobile screen media use among children aged 0-8: a systematic review. BMJ open, 7(10).

Paul, R., Looney, S. S., \& Dahm, P. S. (1991). Communication and socialization skills at ages 2 and 3 in "late-talking" young children. Journal of Speech, Language, and Hearing Research, 34(4), 858-865.

Peterson, R. A., \& Brown, S. P. (2005). On the use of beta coefficients in meta-analysis. Journal of Applied Psychology, 90(1), 175.

[Record \#177 is using a reference type undefined in this output style.]

Phillips, D. A., \& Shonkoff, J. P. (2000). From neurons to neighborhoods: The science of early childhood development. National Academies Press.

Poulain, T., Vogel, M., Neef, M., Abicht, F., Hilbert, A., Genuneit, J., Korner, A., \& Kiess, W. (2018, Apr 21). Reciprocal Associations between Electronic Media Use and Behavioral Difficulties in Preschoolers. Int J Environ Res Public Health, 15(4). https://doi.org/10.3390/ijerph15040814

Press, R. (2015). Developmental milestones of young children. Redleaf Press. 
Quintana, D. S. (2015). From pre-registration to publication: a non-technical primer for conducting a meta-analysis to synthesize correlational data. Frontiers in psychology, 6 , 1549.

Radesky, J. S., \& Christakis, D. A. (2016). Increased screen time: implications for early childhood development and behavior. Pediatric Clinics, 63(5), 827-839.

Radesky, J. S., Schumacher, J., \& Zuckerman, B. (2015). Mobile and interactive media use by young children: the good, the bad, and the unknown. Pediatrics, 135(1), 1-3.

Radesky, J. S., Silverstein, M., Zuckerman, B., \& Christakis, D. A. (2014). Infant SelfRegulation and Early Childhood Media Exposure. Pediatrics, 133(5), e1172. https://doi.org/10.1542/peds.2013-2367

Radesky, J. S., Weeks, H. M., Ball, R., Schaller, A., Yeo, S., Durnez, J., Tamayo-Rios, M., Epstein, M., Kirkorian, H., \& Coyne, S. (2020). Young children's use of smartphones and tablets. Pediatrics.

Rhodes, A. (2017). Screen time and kids: What's happening in our homes. Detailed report. Melbourne (VIC): The Royal Children's Hospital Melbourne.

Rubin, K. H., Coplan, R. J., \& Bowker, J. C. (2009). Social withdrawal in childhood. Annual review of psychology, 60, 141-171. https://doi.org/10.1146/annurev.psych.60.110707.163642

Sadeh, A. (2003). Development of the sleep-wake system and its relationship to children's psychosocial development. Encyclopedia of Early Childhood Development, 1-10.

Sanders, W., Parent, J., Forehand, R., Sullivan, A. D., \& Jones, D. J. (2016). Parental perceptions of technology and technology-focused parenting: Associations with youth screen time. Journal of Applied Developmental Psychology, 44, 28-38. 
Sarwar, M., \& Soomro, T. R. (2013). Impact of smartphone's on society. European journal of scientific research, 98(2), 216-226.

Shonkoff, J. P. (2010). Building a new biodevelopmental framework to guide the future of early childhood policy. Child development, 81(1), 357-367.

Sigelman, C. K., \& Rider, E. A. (2014). Life-span human development. Cengage Learning.

Smith, A., \& Page, D. (2015). US smartphone use in 2015. Pew Research Center, 1.

Suglia, S. F., Duarte, C. S., Chambers, E. C., \& Boynton-Jarrett, R. (2012). Cumulative social risk and obesity in early childhood. Pediatrics, 129(5), e1173-e1179.

Suglia, S. F., Duarte, C. S., Chambers, E. C., \& Boynton-Jarrett, R. (2013). Social and behavioral risk factors for obesity in early childhood. Journal of developmental and behavioral pediatrics: $J D B P, 34(8), 549$.

Taylor, G., Monaghan, P., \& Westermann, G. (2017). Investigating the association between children's screen media exposure and vocabulary size in the UK. Journal of Children and Media, 12(1), 51-65. https://doi.org/10.1080/17482798.2017.1365737

Thakkar, R. R., Garrison, M. M., \& Christakis, D. A. (2006). A systematic review for the effects of television viewing by infants and preschoolers. Pediatrics, 118(5), 2025-2031.

Thompson, D. A., \& Christakis, D. A. (2005). The association between television viewing and irregular sleep schedules among children less than 3 years of age. Pediatrics, 116(4), 851-856.

Trawick-Smith, J. (2013). Early childhood development: A multicultural perspective. Pearson Higher Ed. 
Twenge, J. M., Hisler, G. C., \& Krizan, Z. (2019). Associations between screen time and sleep duration are primarily driven by portable electronic devices: Evidence from a populationbased study of US children ages 0-17. Sleep medicine, 56, 211-218.

van den Heuvel, M., Ma, J., Borkhoff, C. M., Koroshegyi, C., Dai, D. W., Parkin, P. C., Maguire, J. L., \& Birken, C. S. (2019). Mobile media device use is associated with expressive language delay in 18-month-old children. Journal of Developmental and Behavioral Pediatrics, 40(2), 99.

Vatavu, R.-D., Cramariuc, G., \& Schipor, D. M. (2015). Touch interaction for children aged 3 to 6 years: Experimental findings and relationship to motor skills. International Journal of Human-Computer Studies, 74, 54-76.

Viechtbauer, W. (2010). Conducting meta-analyses in R with the metafor package. Journal of statistical software, 36(3), 1-48.

Wartella, E., Rideout, V., Lauricella, A. R., \& Connell, S. (2013). Parenting in the age of digital technology. Report for the center on media and Human development school of communication Northwestern University.

Weigel, D. J., Martin, S. S., \& Bennett, K. K. (2006). Contributions of the home literacy environment to preschool - aged children's emerging literacy and language skills. Early Child Development and Care, 176(3-4), 357-378.

World Health Organization. (2019). Guidelines on physical activity, sedentary behaviour and sleep for children under 5 years of age. World Health Organization.

Wu, X., Tao, S., Rutayisire, E., Chen, Y., Huang, K., \& Tao, F. (2017). The relationship between screen time, nighttime sleep duration, and behavioural problems in preschool children in China. European child \& adolescent psychiatry, 26(5), 541-548. 
Xie, H., Peng, J., Qin, M., Huang, X., Tian, F., \& Zhou, Z. (2018). Can touchscreen devices be used to facilitate young children's learning? A meta-analysis of touchscreen learning effect. Frontiers in psychology, 9, 2580.

Yang, Z., Asbury, K., \& Griffiths, M. D. (2019, 06 / 15 /). An Exploration of Problematic Smartphone Use among Chinese University Students: Associations with Academic Anxiety, Academic Procrastination, Self-Regulation and Subjective Wellbeing [Article]. International Journal of Mental Health and Addiction, 17(3), 596-614. https://doi.org/10.1007/s11469-018-9961-1

Zhang, Z., Sousa-Sá, E., Pereira, J. R., Okely, A. D., Feng, X., \& Santos, R. (2021). Correlates of sleep duration in early childhood: a systematic review. Behavioral Sleep Medicine, 19(3), 407-425.

Zhao, J., Zhang, Y., Jiang, F., Ip, P., Ho, F. K. W., Zhang, Y., \& Huang, H. (2018). Excessive screen time and psychosocial well-being: the mediating role of body mass index, sleep duration, and parent-child interaction. The Journal of pediatrics, 202, 157-162. e151.

Zhu, R., Fang, H., Chen, M., Hu, X., Cao, Y., Yang, F., \& Xia, K. (2020). Screen time and sleep disorder in preschool children: identifying the safe threshold in a digital world. Public Health, 186, 204-210.

Zimmerman, F. J., \& Christakis, D. A. (2005). Children's television viewing and cognitive outcomes: a longitudinal analysis of national data. Archives of pediatrics \& adolescent medicine, 159(7), 619-625.

Zimmerman, F. J., Christakis, D. A., \& Meltzoff, A. N. (2007). Associations between media viewing and language development in children under age 2 years. The Journal of pediatrics, 151(4), 364-368. 
Table 1

Findings for Association between Smartphone and Tablet Use and Psychosocial Factors in Young Children

\begin{tabular}{llllll}
\hline $\begin{array}{l}\text { Author/s } \\
\text { (Year): }\end{array}$ & Sample characteristics & Type of screen use & $\begin{array}{l}\text { Developmental factor } \\
\text { and measure }\end{array}$ & Key findings of association & $\begin{array}{l}\text { Covariates accounted/ } \\
\text { controlled for }\end{array}$ \\
Country & & & & $\begin{array}{l}\text { Overall } \\
\text { quality } \\
\text { (Risk of } \\
\text { bias) }\end{array}$
\end{tabular}

Young children (toddlers and preschool children)

\begin{tabular}{|c|c|c|}
\hline $\begin{array}{l}* \text { McDaniel } \\
\text { and } \\
\text { Radesky } \\
(2020) \text { : } \\
\text { USA }\end{array}$ & $\begin{array}{l}183 \text { heterosexual couples } \\
\text { with young children } \\
\text { aged } 1 \text { to } 5 \text { years }(\mathrm{M}= \\
3, \mathrm{SD}=1.2 \text { years, } 45 \% \\
\text { male) }\end{array}$ & $\begin{array}{l}\text { Smartphone and table } \\
\text { Average use duration } \\
\text { day (hours/day) }\end{array}$ \\
\hline $\begin{array}{l}\text { \#Cho and } \\
\text { Lee (2017): } \\
\text { South } \\
\text { Korea }\end{array}$ & $\begin{array}{l}303 \text { parents of young } \\
\text { children aged } 1-6 \text { years } \\
\text { (prior to elementary } \\
\text { school entry, } 51 \% \text { male) }\end{array}$ & $\begin{array}{l}\text { Smartphone addictiol } \\
\text { proneness reported by } \\
\text { parents }\end{array}$ \\
\hline
\end{tabular}

Korea school entry, $51 \%$ male)

Toddlers

*Lin et al. $\quad 161$ primary caregivers

(2020): $\quad$ of toddlers $(\mathrm{M}=2.14$,

Taiwan $\quad \mathrm{SD}=0.45$ years, $53 \%$

male)

*Levine et 326 parents of toddlers

al. (2019): $\quad(\mathrm{M}=1.43, \mathrm{SD}=0.83$

USA years, $58 \%$ male)

Preschool children

day (hours/day) and with parents (sixFrequently" $=5$ )
Externalizing behavior: Greater child externalizing behavior significantly

Child Behavior Checklist predicted greater tablet use (not phone use) at

(CBCL)

Problematic behavior:

Korea Personality

Inventory for Children

(K-PIC) and Preschooler

Behavior Questionnaire

(PBQ); Emotional

intelligence: reported by

parents

Smartphone and tablet:

Internalizing and

Average use duration per

externalizing behavioral

problems: CBCL 11/2-5

Smartphone and tablet: Frequency of use alone point scale anchored by "Never" $=0$ and "Very
Self-regulation: Infant-

Toddler Symptom

Checklist (ITSC) follow-up via parenting stress (based on structural equation modeling). However, greater smartphone and tablet use did not significantly predict later

externalizing behavior.

All smartphone addiction tendencies were significantly positively associated with problematic

Children who spent more time on smartphone and tablets were more likely to have more emotional problems, anxious/ depressive symptoms, social withdrawal and aggressive behavior, even after controlling for confounding variables.

Child age, parents' gender,

Strong

education, and depression levels

(Low)

behavior, and all addiction tendencies except

Parental age, level of education, and occupation, children's age

Acceptable and daily smartphone usage

(Moderate)

Child's sex and age, prematurity, only child status, primary caregiver, and parents' education

Strong (Low) Greater frequency of use of smartphone and tablets alone by child was significantly predicted by

Educational or non-educational greater child self-dysregulation. motives of parents for children's media use; age and sex of child; parent's education and relationship status 


\begin{tabular}{|c|c|c|}
\hline $\begin{array}{l}\text { "Lee and Park } \\
\text { (2018): South } \\
\text { Korea }\end{array}$ & $\begin{array}{l}171 \text { mothers of } \\
\text { preschool children } \\
(\mathrm{M}=4.63, \mathrm{SD}= \\
1.06 \text { years, } 53 \% \\
\text { male) }\end{array}$ & $\begin{array}{l}\text { Smartphones over- } \\
\text { dependence tendency: } \\
\text { The smartphone over- } \\
\text { immersion evaluation } \\
\text { scale; Average duration } \\
\text { of use (min or hours/day) }\end{array}$ \\
\hline $\begin{array}{l}\text { *Nathanson and } \\
\text { Beyens } \\
\text { (2018b): USA }\end{array}$ & $\begin{array}{l}402 \text { mothers of } \\
\text { preschool children } \\
(\mathrm{M}= \\
4.0, \mathrm{SD}=0.80 \\
\text { years, } 52 \% \text { male })\end{array}$ & $\begin{array}{l}\text { Tablets only: Average } \\
\text { daily duration of use } \\
\text { (min /day) and evening } \\
\text { use (min) }\end{array}$ \\
\hline $\begin{array}{l}\text { Poulain et al. } \\
\text { (2018): } \\
\text { Germany }\end{array}$ & $\begin{array}{l}527 \text { preschool } \\
\text { children }(\mathrm{M}=3.81, \\
\mathrm{SD}=0.89 \text { years, } \\
52 \% \text { male }) \text { and their } \\
\text { parents }\end{array}$ & $\begin{array}{l}\text { Mobile phones only: } \\
\text { Duration of use per day } \\
\text { formed into categories of } \\
\text { users vs non-users }\end{array}$ \\
\hline $\begin{array}{l}\text { *Lawrence et } \\
\text { al. (2020): USA }\end{array}$ & $\begin{array}{l}56 \text { preschool } \\
\text { children }(\mathrm{M}=3.12, \\
\mathrm{SD}=0.38 \text { years, } \\
54 \% \text { male }) \text { and their } \\
\text { parents }\end{array}$ & $\begin{array}{l}\text { Smartphone and tablet: } \\
\text { Average weekly duration } \\
\text { of use (hours/week) }\end{array}$ \\
\hline $\begin{array}{l}\# \text { Lee et al. } \\
\text { (2015): South } \\
\text { Korea }\end{array}$ & $\begin{array}{l}83 \text { mothers of } \\
\text { preschool children } \\
\text { aged } 4 \text { and } 5 \text { years } \\
(47 \% \text { male) }\end{array}$ & $\begin{array}{l}\text { Smartphone addiction } \\
\text { tendency: Korean } \\
\text { children's internet } \\
\text { addiction observer } \\
\text { diagnosis scale } \\
\text { (modified for } \\
\text { smartphones) }\end{array}$ \\
\hline $\begin{array}{l}\text { \#im and } \\
\text { Hwang (2017): } \\
\text { South Korea }\end{array}$ & $\begin{array}{l}263 \text { preschool } \\
\text { children ( } 4 \text { year old, } \\
53 \% \text { male) }\end{array}$ & $\begin{array}{l}\text { Smart device (mainly } \\
\text { smartphones) immersion } \\
\text { tendency: Modified } \\
\text { 'Internet and child }\end{array}$ \\
\hline
\end{tabular}

Self-regulation: Parent reported self-adjustment tool

Children's smartphone over-dependence tendency was significantly associated with poorer selfregulation, even after controlling for confounding variables.

Temperament i.e., effortful control (EC): Early Childhood

Behavior Questionnaire (ECB)

Emotional, conduct,

hyperactivity/inattention and peer problems: Strengths and

Difficulties

Questionnaire (SDQ)

Self-regulation:

Children's Behavior

Questionnaire or ECBQ

reported by parents and

11-task behavioral self-

regulation battery

administered to children

Problem behavior:

Preschool behavior

questionnaire

Self-regulation:

Modified Kendall and

Willcox's Self-Control

Rating scale; Prosocial

Tablet use was significantly negatively associated with effortful control. However, this relationship was moderated by total sleep time (i.e., this

association was significant only when the child sleep (i.e., the association was significant via

quality indicators of sleep).

Baseline use of mobile phones was significantly associated with more conduct problems and hyperactivity or inattention at follow-up. Further, peer relationship problems at baseline was significantly associated with greater mobile phone use at follow-up. No significant associations were present between mobile phone use and emotional problems at baseline/ follow-up.

Children's mean weekly use of smartphone and tablets was significantly associated with lower behaviorally assessed self-regulation. However, there was no significant association with parentreported self-regulation. positively correlated with hyperactive-distractible behavior. However, there was no significant
Mother's occupation, child's age, smartphone usage frequency,

mother's average daily

smartphone usage time, parental

efficacy and maternal interactions received less sleep) and was mediated by quality of

Smartphone addiction tendency was significantly correlation between smartphone addiction tendency and hostile-aggressive or anxious-fearful behavior.

Age, gender, socio-economic status (SES), year of data acquisition, other baseline predictors and the outcomes

Use of traditional media like TV, Acceptable age of first use of any screen (Moderate) based media, parent education, family income, child age and sex. 


\begin{tabular}{|c|c|c|c|c|c|c|}
\hline & & $\begin{array}{l}\text { addiction diagnosis } \\
\text { scale' developed by the } \\
\text { Korea Information } \\
\text { Society Agency }\end{array}$ & $\begin{array}{l}\text { behavior: Prosocial } \\
\text { Behavior Questionnaire } \\
\text { (PBQ) }\end{array}$ & $\begin{array}{l}\text { immersion tendency. Self-regulation also } \\
\text { significantly mediated the relationship between } \\
\text { prosocial behavior and smart device immersion } \\
\text { tendency. }\end{array}$ & & \\
\hline $\begin{array}{l}\text { McNeill et al. } \\
(2019) \text { : } \\
\text { Australia }\end{array}$ & $\begin{array}{l}185 \text { preschool } \\
\text { children }(\mathrm{M}=4.2, \\
\mathrm{SD}=0.6 \text { years, } 61 \% \\
\text { male) and their } \\
\text { parents }\end{array}$ & $\begin{array}{l}\text { Smartphone and tablet } \\
\text { app use only: Categories } \\
\text { of non-users }(0 \mathrm{~min} / \mathrm{d}) \\
\text { low-dose users }(1-29 \\
\mathrm{min} / \mathrm{d}) ; \text { or high-dose } \\
\text { users }(\geq 30 \mathrm{~min} / \mathrm{d})\end{array}$ & $\begin{array}{l}\text { Externalizing and } \\
\text { internalizing behavior, } \\
\text { total difficulties, } \\
\text { prosocial behavior: SDQ }\end{array}$ & $\begin{array}{l}\text { App use on smartphone and tablets at baseline did } \\
\text { not significantly predict scores on the psychosocial } \\
\text { domains of development at follow-up. }\end{array}$ & $\begin{array}{l}\text { Age, sex, suburb-level SES, } \\
\text { parental education, participation } \\
\text { in sports, physical activity } \\
\text { duration, home learning } \\
\text { environment, sleep duration, } \\
\text { total program viewing, and } \\
\text { childcare-level clustering }\end{array}$ & $\begin{array}{l}\text { Acceptable } \\
\text { (Moderate) }\end{array}$ \\
\hline $\begin{array}{l}*^{*} \text { Moon et al. } \\
\text { (2019): South } \\
\text { Korea }\end{array}$ & $\begin{array}{l}117 \text { preschool } \\
\text { children }(\mathrm{M}=4.5, \\
\mathrm{SD}=0.9 \text { years, } 54 \% \\
\text { male }) \text { and their } \\
\text { parents }\end{array}$ & $\begin{array}{l}\text { Smartphone and tablet: } \\
\text { Average frequency of } \\
\text { use per week and } \\
\text { duration of use } \\
\text { (hours/day) }\end{array}$ & $\begin{array}{l}\text { Social development: The } \\
\text { parent reported Korean- } \\
\text { developmental screening } \\
\text { test }\end{array}$ & $\begin{array}{l}\text { Greater average use of smartphone and tablets was } \\
\text { not significantly correlated with social } \\
\text { developmental levels. }\end{array}$ & NA & $\begin{array}{l}\text { Acceptable } \\
\text { (Moderate) }\end{array}$ \\
\hline $\begin{array}{l}\text { *Gülay } \\
\text { Ogelman et al. } \\
\text { (2016): Turkey }\end{array}$ & $\begin{array}{l}162 \text { preschool } \\
\text { children }(\mathrm{M}=5.42, \\
\mathrm{SD}=0.45 \text { years, } \\
56 \% \text { male })\end{array}$ & $\begin{array}{l}\text { Smartphone and tablet: } \\
\text { Duration of use on } \\
\text { weekdays and weekends }\end{array}$ & $\begin{array}{l}\text { Social skills: Social } \\
\text { Skills Evaluation scale } \\
\text { (SSES); Social status, } \\
\text { i.e., social preference } \\
\text { and social impact: } \\
\text { Picture sociometry scale }\end{array}$ & $\begin{array}{l}\text { Children's smartphone and tablet use was not } \\
\text { significantly associated with social skills. Tablet } \\
\text { use was not significantly associated with social } \\
\text { status. However, smartphone use was significantly } \\
\text { associated with lower social preferences in } \\
\text { children. }\end{array}$ & $\begin{array}{l}\text { Duration of } \mathrm{TV} \text {, and portable } \\
\text { computers use and duration of } \\
\text { overall media use }\end{array}$ & $\begin{array}{l}\text { Acceptable } \\
\text { (Moderate) }\end{array}$ \\
\hline
\end{tabular}

Note: *included in the meta-analysis relating to amount of use; ${ }^{*}$ included in the meta-analysis relating to perceptions of problematic use 
Table 2

Findings for Association between Smartphone and Tablet Use, Cognitive and Language Factors in Young Children

\begin{tabular}{|c|c|c|c|c|c|c|}
\hline $\begin{array}{l}\text { Author/s } \\
\text { (Year): } \\
\text { Country }\end{array}$ & $\begin{array}{l}\text { Sample } \\
\text { characteristics }\end{array}$ & Type of screen use & $\begin{array}{l}\text { Developmental factor and } \\
\text { measure }\end{array}$ & Key findings of association & $\begin{array}{l}\text { Covariates accounted/ } \\
\text { controlled for }\end{array}$ & $\begin{array}{l}\text { Overall } \\
\text { quality (Risk } \\
\text { of bias) }\end{array}$ \\
\hline \multicolumn{7}{|l|}{ Toddlers } \\
\hline $\begin{array}{l}\text { *Lin et al. } \\
(2020): \\
\text { Taiwan }\end{array}$ & $\begin{array}{l}161 \text { primary } \\
\text { caregivers of } \\
\text { toddlers }(\mathrm{M}= \\
2.14, \mathrm{SD}=0.45 \\
\text { years, } 53 \% \text { male })\end{array}$ & $\begin{array}{l}\text { Smartphone and tablet: } \\
\text { Average use duration per } \\
\text { day (hours/day) }\end{array}$ & $\begin{array}{l}\text { Language development/ delay: } \\
\text { Communication and Language } \\
\text { Screening Test for Birth to Three } \\
\text { Chinese-Speaking Infant- } \\
\text { Toddlers (CLST) }\end{array}$ & $\begin{array}{l}\text { Smartphone and tablet use was significantly correlated } \\
\text { with language development. However, when } \\
\text { confounding variables were controlled for, the } \\
\text { association was no longer significant, i.e., children who } \\
\text { spent more time on smartphone and tablets were not } \\
\text { more likely to have language delay. }\end{array}$ & $\begin{array}{l}\text { Child's sex, age, } \\
\text { prematurity, only child } \\
\text { status, primary caregiver, } \\
\text { and parents' education }\end{array}$ & Strong (Low) \\
\hline $\begin{array}{l}\text { *Taylor et al. } \\
\text { (2017): UK }\end{array}$ & $\begin{array}{l}131 \text { toddlers }(\mathrm{M}= \\
1.67, \mathrm{SD}=0.69 \\
\text { years, } 47 \% \text { male }) \\
\text { and their parents }\end{array}$ & $\begin{array}{l}\text { Smartphone and tablet: } \\
\text { Duration of use on a } \\
\text { typical day (min or } \\
\text { hours/day) }\end{array}$ & $\begin{array}{l}\text { Vocabulary production and } \\
\text { comprehension: Lincoln UK- } \\
\text { Communicative Development } \\
\text { Inventory (CDI) for Toddlers }\end{array}$ & $\begin{array}{l}\text { Time spent engaging with smartphone and tablets was } \\
\text { not significantly associated with vocabulary } \\
\text { comprehension or production scores. }\end{array}$ & Child's age & $\begin{array}{l}\text { Acceptable } \\
\text { (Moderate) }\end{array}$ \\
\hline $\begin{array}{l}\text { *van den } \\
\text { Heuvel et al. } \\
(2019): \\
\text { Canada }\end{array}$ & $\begin{array}{l}893 \text { parents of } \\
\text { toddlers }(\mathrm{M}=1.56 \\
\text { years, } 54 \% \text { males })\end{array}$ & $\begin{array}{l}\text { Smartphone and tablet : } \\
\text { Average daily duration of } \\
\text { use (min/day) }\end{array}$ & $\begin{array}{l}\text { Expressive speech delay and } \\
\text { other communication delays: } \\
\text { Infant toddler checklist (ITC) }\end{array}$ & $\begin{array}{l}\text { For children who used a smartphone and tablet, each } \\
\text { additional } 30 \text {-minute increase in daily smartphone and } \\
\text { tablet use was significantly associated with increased } \\
\text { odds of parent-reported expressive speech delay. } \\
\text { However, use was not significantly associated with } \\
\text { other parent-reported communication delays. }\end{array}$ & $\begin{array}{l}\text { Child sex, household } \\
\text { income, maternal } \\
\text { education, the } 3 \\
\text { temperament domains, } \\
\text { and participation year, } \\
\text { non-smartphone and } \\
\text { tablet use, and parent } \\
\text { smartphone and tablet } \\
\text { use }\end{array}$ & Strong (Low) \\
\hline $\begin{array}{l}\text { Borajy et al. } \\
\text { (2019): Saudi } \\
\text { Arabia }\end{array}$ & $\begin{array}{l}74 \text { toddlers (aged } \\
18 \text { to } 36 \text { months) } \\
\text { and their parents }\end{array}$ & $\begin{array}{l}\text { Smartphone and tablet: } \\
\text { Duration of use } \\
\text { (hours/day) }\end{array}$ & $\begin{array}{l}\text { Speech delay: Speech and } \\
\text { language screening guidelines } \\
\text { assessed by pediatric residents }\end{array}$ & $\begin{array}{l}\text { Child's smartphone and tablet use did not significantly } \\
\text { influence the odds of having speech delay. }\end{array}$ & NA & Weak (High) \\
\hline \multicolumn{7}{|c|}{ Preschool children } \\
\hline $\begin{array}{l}{ }^{* *} \text { Moon et al. } \\
\text { (2019): South } \\
\text { Korea }\end{array}$ & $\begin{array}{l}117 \text { preschool } \\
\text { children }(\mathrm{M}=4.5 \\
\mathrm{SD}=0.9 \text { years, } \\
54 \% \text { males }) \text { and } \\
\text { their parents }\end{array}$ & $\begin{array}{l}\text { Smartphone and tablet: } \\
\text { Average frequency of use } \\
\text { per week and duration of } \\
\text { use (hours/day) }\end{array}$ & $\begin{array}{l}\text { Language development i.e., } \\
\text { receptive and expressive } \\
\text { language: Preschool receptive- } \\
\text { expressive language scale; } \\
\text { Cognitive developmental levels: } \\
\text { Korean Developmental Screening }\end{array}$ & $\begin{array}{l}\text { Child's smartphone and tablet use time was } \\
\text { significantly negatively correlated with expressive } \\
\text { language development in three-year old children. } \\
\text { However, there were no such relations in four or five } \\
\text { year old children. There were no significant relations } \\
\text { between use and cognitive developmental levels across }\end{array}$ & NA & $\begin{array}{l}\text { Acceptable } \\
\text { (Moderate) }\end{array}$ \\
\hline
\end{tabular}




\begin{tabular}{|c|c|c|c|}
\hline $\begin{array}{l}\text { *Neumann } \\
(2014): \\
\text { Australia }\end{array}$ & $\begin{array}{l}109 \text { pre-school } \\
\text { children }(\mathrm{M}= \\
4.22, \mathrm{SD}=0.52 \\
\text { years, } 52 \% \text { male }) \\
\text { and their parents }\end{array}$ & $\begin{array}{l}\text { Tablets only: Access } \\
\text { (number of tablets at } \\
\text { home) and average } \\
\text { duration of use (min/day) }\end{array}$ & $\begin{array}{l}\text { Emergent literacy skills: Early } \\
\text { literacy measures for letter name } \\
\text { and sound knowledge, numeral } \\
\text { identification, name writing, print } \\
\text { concepts and word reading }\end{array}$ \\
\hline $\begin{array}{l}\text { *Kotrla Topić } \\
\text { et al. }(2020) \text { : } \\
\text { Croatia }\end{array}$ & $\begin{array}{l}97 \text { pre-school } \\
\text { children aged 6-7 } \\
\text { years (56\% male) } \\
\text { and their parents }\end{array}$ & $\begin{array}{l}\text { Smartphone and tablet: } \\
\text { Duration of use on a } \\
\text { typical day for } \\
\text { entertainment purposes } \\
\text { (hours/day) }\end{array}$ & $\begin{array}{l}\text { Literacy skills: Letter recognition } \\
\text { test }\end{array}$ \\
\hline $\begin{array}{l}\text { *Hutton et al. } \\
\text { (2020): USA }\end{array}$ & $\begin{array}{l}69 \text { pre-school } \\
\text { children }(\mathrm{M}= \\
4.33, \mathrm{SD}=0.67 \\
\text { years, } 49 \% \text { male }) \\
\text { and their parents }\end{array}$ & $\begin{array}{l}\text { Smartphone and tablet: } \\
\text { Access to child's own } \\
\text { device assessed using the } \\
\text { ScreenQ novel survey }\end{array}$ & $\begin{array}{l}\text { Cognitive abilities; Emerging } \\
\text { literacy skills: Get Ready to Read } \\
\text { (GRTR) and The Reading House } \\
\text { (TRH); Expressive vocabulary } \\
\text { test (EVT-2); Preschool \& } \\
\text { Primary Inventory of } \\
\text { Phonological Awareness, } \\
\text { rhyming subscale (PIPA); } \\
\text { Comprehensive Test of } \\
\text { Phonological Processing } \\
\text { (CTOPP), Rapid Object Naming } \\
\text { subtest) }\end{array}$ \\
\hline $\begin{array}{l}\text { *Jusiené et al. } \\
\text { (2020): } \\
\text { Lithuania }\end{array}$ & $\begin{array}{l}190 \text { pre-school } \\
\text { children }(\mathrm{M}= \\
4.90, \mathrm{SD}=0.61 \\
\text { years, } 56 \% \text { male }) \\
\text { and their parents }\end{array}$ & $\begin{array}{l}\text { MTSD: Average daily } \\
\text { duration of use per day } \\
\text { (min/day) }\end{array}$ & $\begin{array}{l}\text { Executive functioning; Mental } \\
\text { set shifting: Shape School Task; } \\
\text { Working memory: Missing Scan } \\
\text { Task; Inhibitory control: Head } \\
\text { and Feet Task }\end{array}$ \\
\hline $\begin{array}{l}\text { McNeill et al. } \\
\text { (2019): } \\
\text { Australia }\end{array}$ & $\begin{array}{l}185 \text { preschool } \\
\text { children }(\mathrm{M}=4.2, \\
\mathrm{SD}=0.6 \text { years, } \\
61 \% \text { males }) \text { and } \\
\text { their parents }\end{array}$ & $\begin{array}{l}\text { Smartphone and tablet app } \\
\text { use only: Categories of } \\
\text { non-users ( } 0 \mathrm{~min} / \mathrm{d}) \text {; low- } \\
\text { dose users }(1-29 \mathrm{~min} / \mathrm{d}) \text {; } \\
\text { or high-dose users ( } \geq 30 \\
\mathrm{~min} / \mathrm{d} \text { ) }\end{array}$ & $\begin{array}{l}\text { Executive functioning: Visual- } \\
\text { spatial working memory: "Mr. } \\
\text { Ant" task; Phonological } \\
\text { working memory: "Not This" } \\
\text { task, inhibition: Go/No-Go task; } \\
\text { shifting: Dimensional Change } \\
\text { Card Sort Task }\end{array}$ \\
\hline
\end{tabular}

all ages

Time spent on tablets was not significantly associated Child's age

Weak (High) with emergent literacy skills of children. However,

children with greater access to tablets were found to

have higher letter sound and name writing skills.

Time spent on smartphone and tablets for entertainmen purposes was significantly negatively correlated with letter recognition. However, this association was no longer significant, when other variables were also included in the regression model.

Access to child's own smartphone and tablet was significantly negatively correlated with TRH score of emergent literacy and CTOPP score of processing speed. Access to child's own smartphone and tablet was only marginally significantly (negatively) correlated with the other language and literacy measures.

Executive functioning measures were not significantly predicted by MTSD use.

Age, parental education

Acceptable (Moderate)

High-dose app users at baseline had a significantly lower inhibition score at follow-up than low-dose app users; App use did not significantly predict other participation in sports,

Age, sex, suburb-level SES, parental education,

Acceptable physical activity duration, home learning environment, sleep duration, total program viewing, and childcarelevel clustering

Note: *included in the meta-analysis relating to amount of use; ${ }^{\#}$ included in the meta-analysis relating to perceptions of problematic use 
Table 3

Findings for Associations between Smartphone and Tablet Use and Sleep Factors in Young Children

\begin{tabular}{|c|c|c|c|c|c|c|}
\hline $\begin{array}{l}\text { Author/s } \\
\text { (Year): } \\
\text { Country }\end{array}$ & $\begin{array}{l}\text { Sample } \\
\text { characteristics }\end{array}$ & Type of screen use & $\begin{array}{l}\text { Developmental factor and } \\
\text { measure }\end{array}$ & Key findings of association & Covariates accounted/ controlled for & $\begin{array}{l}\text { Overall } \\
\text { quality } \\
\text { (Risk of } \\
\text { bias) }\end{array}$ \\
\hline
\end{tabular}

Toddlers

*Cheung et 715 toddlers $(\mathrm{M} \quad$ Tablets only:

al. (2017):

UK

$=1.63, \mathrm{SD}=$

Average daily

0.69 years, $53 \%$

male) and their

parents

duration of use on

typical day (min

/day)

Chindamo 1117 parents of Smartphone and

et al. toddlers $(\mathrm{M}=$

Night-time sleep, daytime

tablet: Frequency of

(2019):

$2.11, \mathrm{SD}=0.03$

years, $51 \%$

habitual use (times

used/ week)

male)

Preschool children

*Nathanson $\dagger_{402}$ mothers of

and Beyens preschool

(2018b): $\quad$ children $(\mathrm{M}=$

$\begin{array}{ll}\text { USA } & \text { children }(\mathrm{M}= \\ & 4.0, \mathrm{SD}=0.80\end{array}$

years, $52 \%$

male)

Tablets only:

Average daily

duration of use (min

/day) and evening

use (min)

Night-time and daytime sleep duration, night time

awakenings, sleep onset:

The Brief Screening

Questionnaire for Infant

Sleep Problems (BISQ38)

sleep and mean sleep onset

latency: reported by parents

Sleep quality (bedtime resistance and daytime sleepiness): Children's Sleep Habits Questionnaire

Total sleep duration reported by parents

Sleep quality (bedtime

Nathanson and Beyens

(2018a):

USA

$\dagger_{402 \text { mothers of }}$

Smartphone an tablet: Average daily duration of use on children $(\mathrm{M}=$ $4.0, \mathrm{SD}=0.80$ typical weekday and Habits Questionnaire (CSHQ); Sleep quantity: associated with shorter total sleep time and longer sleep onset latency, i.e., everyday use of smartphone and tablets significantly raised the odds of a shorter total sleep time, and their frequent (3-5 times a week) or everyday use raised the odds of a longer sleep onset latency irrespective of other confounding factors.

Tablet use was significantly associated with reduced overal amount of sleep and delayed sleep onset. However, tablet use was not significantly associated with frequency of night awakenings.

The relation between tablet use and effortful control was moderated by children's sleep time, i.e., Tablet use was

significantly negatively related to effortful control only among children who received less sleep. Also, the relation between evening tablet use and effortful control was mediated by sleep quality, i.e., evening tablet use was significantly related to late bedtimes, more bedtime resistance, and worse sleep duration, and these indicators of poor sleep quality, in turn, significantly predicted weaker effortful control.

Daily and evening tablet use was significantly associated with greater bedtime resistance and compromised sleep duration, after controlling for confounding factors. Daily or evening smartphone and tablet use was not significantly associated with daytime sleepiness. Smartphone use was not significantly related
Average duration of daily TV exposure, child's age and sex, mother's education

Acceptable

(Moderate) sleepiness): Children's Sleep (CSHQ); Sleep quantity: preschool, mother's education, mother's

income, and mother's employment status.

(Moderate)
Gender, having siblings, attending

kindergarten, breastfeeding, age and parents'

formal education, children's habitual

bedtime routines recreational activities (e.g.,

TV viewing) and behavioral characteristics

(e.g., temperament)

Child's age, the child's sex, mother's employment status, number of days the child attends childcare, mother's education, household income, TV viewing

Child's age, number of days the child attends Acceptable

Acceptable

(Moderate)

TV viewing 

years, $52 \% \quad$ (hours/day)
male)
Total sleep duration reported
by parents
to sleep duration nor bedtime resistance. However, evening smartphone use was significantly associated with bedtime resistance.

Smartphone and

Beyens and $\dagger_{402}$ mothers of

Nathanson preschool

(2019): $\quad$ children $(\mathrm{M}=$

USA

children $(\mathrm{M}=$

years, $52 \%$

blet: Average daily

duration of use on

typical weekday and

weekend

male) (hours/day)

*Lan et al. 2903 parents of

(2020):

preschool

Smartphone and

tablet use (and other

portable devices):

Average daily

$3.9, \mathrm{SD}=1.0$

duration of use on

years, $44 \%$

typical weekday and

weekend ( $\mathrm{min} /$ day)

Zhu et al. 2278 parents of Smartphone and

(2020): preschool tablet use: Average

China children (aged 3 daily duration of use

to 6 years, $51 \%$ on typical weekday

male)
Bedtime, wake time,

consolidation: Reported by

Heavier evening and daily tablet use were associated with late bedtimes and later wake times, but not lower amount of sleep. Smartphone use was not significantly associated with bedtimes nor wake times. However, evening smartphone use was significantly associated with increased naptime sleep. Evening tablet use, and both daily and evening smartphone use were significantly associated with poorer sleep consolidation. independently associated with a reduction in daily sleep duration of 11 and 6 minutes in boys and girls, respectively. Compared to non-portable devices, use of portable ones was more closely associated with short sleep duration.

Sleep disorder: $\mathrm{CSHQ}$

More time spent on phone or tablet was not significantly associated with increased risk of sleep disorder. However, the groups of sleep disorder and non-sleep disorder significantly differed in their phone use.
Sleep duration: Reported by Each additional hour spent on smartphone and tablets was
TV and other electronic devices time, child's age and daycare attendance, mother's education, employment and household income

Age, gender, parental education level, parental work status, housing area, family income, parental age, parental sleep duration and children outdoor physical activity

Child's age, gender, recent history of disease (i.e., asthma, eczema, rhinitis and conjunctivitis), parents' smoking and education and residential distance to the main road.
Acceptable (Moderate)

Acceptable

(Moderate)

\section{Note: ${ }^{\dagger}$ Same sample and data; $*$ included in the meta-analysis relating to amount of use; ${ }^{\#}$ included in the meta-analysis relating to} perceptions of problematic use 


\section{Table 4}

High-level Summary of Evidence of Associations between Smartphone and Tablet Use and Child-Specific Factors in Young Children

\begin{tabular}{llll}
\hline Domain & Factors & Significant negative association & Significant positive association
\end{tabular}

\begin{tabular}{|c|c|c|c|c|}
\hline $\begin{array}{l}\text { Self- } \\
\text { regulation }\end{array}$ & Self-regulation & $\begin{array}{l}\text { Levine et al. (2019); Lee and Park } \\
\text { (2018); Kim and Hwang (2017); } \\
\text { Nathanson and Beyens (2018b); } \\
\text { smartphone and tablet use as predictor: } \\
\text { Lawrence et al. (2020) }\end{array}$ & & $\begin{array}{l}\text { Smartphone and tablet use as outcome: } \\
\text { Lawrence et al. (2020) }\end{array}$ \\
\hline \multirow[t]{2}{*}{$\begin{array}{l}\text { Emotional } \\
\text { factors }\end{array}$} & Internalizing behavior & & $\begin{array}{l}\text { Anxiety, depression and social } \\
\text { withdrawal: Lin et al. (2020) }\end{array}$ & $\begin{array}{l}\text { Smartphone and tablet use as both predictor } \\
\text { and outcome: Poulain et al. (2018); McNeill et } \\
\text { al. (2019); Lee et al. (2015) [Anxious sub-type } \\
\text { of behavior] }\end{array}$ \\
\hline & Emotional intelligence & Cho and Lee (2017) & & \\
\hline \multirow[t]{3}{*}{$\begin{array}{l}\text { Externalizi } \\
\text { ng } \\
\text { behavior }\end{array}$} & Hyperactivity/ Inattention & & $\begin{array}{l}\text { Lee et al. (2015); smartphone } \\
\text { and tablet use as predictor: } \\
\text { Poulain et al. (2018) }\end{array}$ & $\begin{array}{l}\text { Smartphone and tablet use as outcome: } \\
\text { Poulain et al. (2018) }\end{array}$ \\
\hline & Conduct problems & & $\begin{array}{l}\text { Cho and Lee (2017) } \\
\text { [problematic behaviour]; } \\
\text { Smartphone and tablet use as } \\
\text { predictor: Poulain et al. (2018) }\end{array}$ & $\begin{array}{l}\text { Smartphone and tablet use as outcome: } \\
\text { Poulain et al. (2018) }\end{array}$ \\
\hline & Aggression & & $\begin{array}{l}\text { Smartphone and tablet use as } \\
\text { outcome: McDaniel and } \\
\text { Radesky (2020); Lin et al. } \\
(2020)\end{array}$ & $\begin{array}{l}\text { Smartphone and tablet use as predictor: } \\
\text { McNeill et al. (2019); McDaniel and Radesky } \\
(2020)\end{array}$ \\
\hline \multirow{3}{*}{$\begin{array}{l}\text { Social } \\
\text { developme } \\
\text { nt }\end{array}$} & Social skills & $\begin{array}{l}\text { Social preferences: Gülay Ogelman et al. } \\
\text { (2016) }\end{array}$ & & $\begin{array}{l}\text { Moon et al. (2019); Gülay Ogelman et al. } \\
(2016)\end{array}$ \\
\hline & Peer problems & & $\begin{array}{l}\text { Smartphone and tablet use as } \\
\text { outcome: Poulain et al. (2018) }\end{array}$ & $\begin{array}{l}\text { Smartphone and tablet use as predictor: } \\
\text { Poulain et al. (2018) }\end{array}$ \\
\hline & Prosocial behavior & Kim and Hwang (2017) & & \\
\hline Cognitive & Executive functioning & Inhibitory control: McNeill et al. (2019) & & Working memory: McNeill et al. (2019); \\
\hline
\end{tabular}


developme

nt

(Executive functionin

g) Language and speech developme nt (expressive or receptive) Speech development

Vocabulary production and comprehension

Literacy Emergent literacy

Sleep Night-time sleep duration

duration

\section{Sleep Bedtime resistance}

quality Sleep onset

Other factors
Processing speed: Hutton et al. (2020)

Only in 3 year olds: Moon et al. (2019)

Expressive speech delay: van den Heuvel et al. (2019)

Access to own smartphone and tablet: Hutton et al. (2020)

Cheung et al. (2017); Chindamo et al. (2019); Lan et al. (2020); Tablet use: (Nathanson \& Beyens, 2018a, 2018b)

(Nathanson \& Beyens, 2018a, 2018b)

Cheung et al. (2017); Chindamo et al. (2019);

Sleep consolidation: Beyens and Nathanson (2019)
Jusienè et al. (2020); set shifting: Jusienè et al. (2020)

Moon et al. (2019)

Lin et al. (2020); In 4 and 5 year olds: Moon et al. (2019)

Borajy et al. (2019); Other communications delays: van den Heuvel et al. (2019)

Taylor et al. (2017)

Access to tablet: Neumann (2014)

Time spent on tablet: Neumann (2014)

Smartphone use: Nathanson and Beyens (2018a); Beyens and Nathanson (2019)

Night awakenings: Cheung et al. (2017); daytime sleepiness: Nathanson and Beyens (2018a); sleep disorder: Zhu et al. (2020) 


\section{Table 5}

Meta-analytic Correlations of Amount of Smartphone and/or Tablet Use with Psychosocial, Cognitive and Sleep-Related Factors in Young Children

\begin{tabular}{lccccccc}
\hline \multicolumn{1}{c}{ Child Factor } & $k$ & $n$ & $\bar{r}$ & $p$ & {$[95 \% \mathrm{CI}]$} & $\tau$ & $I^{2}$ \\
\hline All child-specific factors & 16 & 7,566 & $-.08^{*}$ & .001 & {$[-.13,-.03]$} & .10 & $73.98 \%$ \\
$\quad$ Psychosocial factors & 12 & 2,629 & -.07 & .115 & {$[-.15, .02]$} & .11 & $72.45 \%$ \\
$\quad$ Self-regulation & 5 & 1,621 & -.03 & .648 & {$[-.18, .11]$} & .15 & $86.44 \%$ \\
Cognitive factors & 10 & 1,589 & -.07 & .143 & {$[-.16, .02]$} & .10 & $56.54 \%$ \\
$\quad$ Executive functioning & 5 & 368 & -.09 & .196 & {$[-.22, .05]$} & .09 & $30.30 \%$ \\
$\quad$ Language-related factors & 9 & 1,399 & -.09 & .090 & {$[-.20, .01]$} & .11 & $58.04 \%$ \\
Sleep-related factors & 4 & 4,181 & $-.15^{*}$ & $<.001$ & {$[-.21,-.08]$} & .06 & $67.75 \%$
\end{tabular}

Note. $k=$ number of samples; $n=$ total sample size; $\bar{r}=$ combined effect size. All child-specific factors represent an overall aggregate.

$* p<.05$ 


\section{Figure 1}

PRISMA flow diagram of study selection

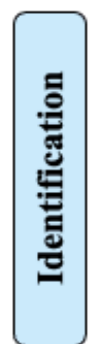

$$
\begin{gathered}
\text { Records identified through database } \\
\text { searching } \\
(\mathrm{n}=1645)
\end{gathered}
$$

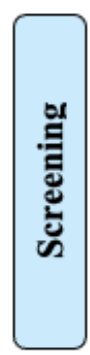

Records after duplicates removed

$$
(\mathrm{n}=1050)
$$
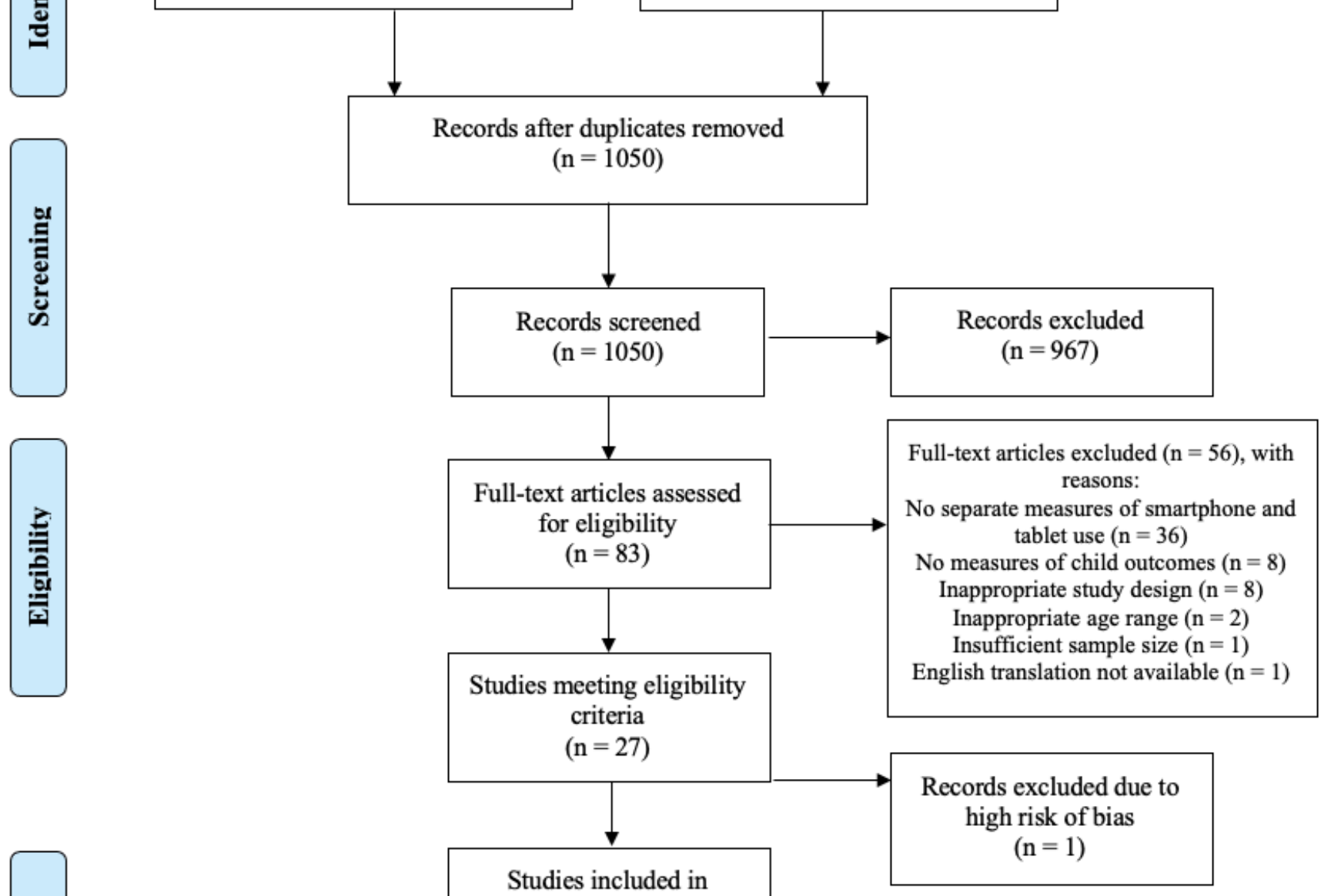
qualitative synthesis $(\mathrm{n}=26)$

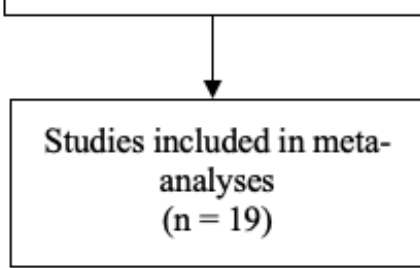


Figure 2

Summary of findings relating to smartphone and tablet use with psychosocial, cognitive and sleep-related factors in young children

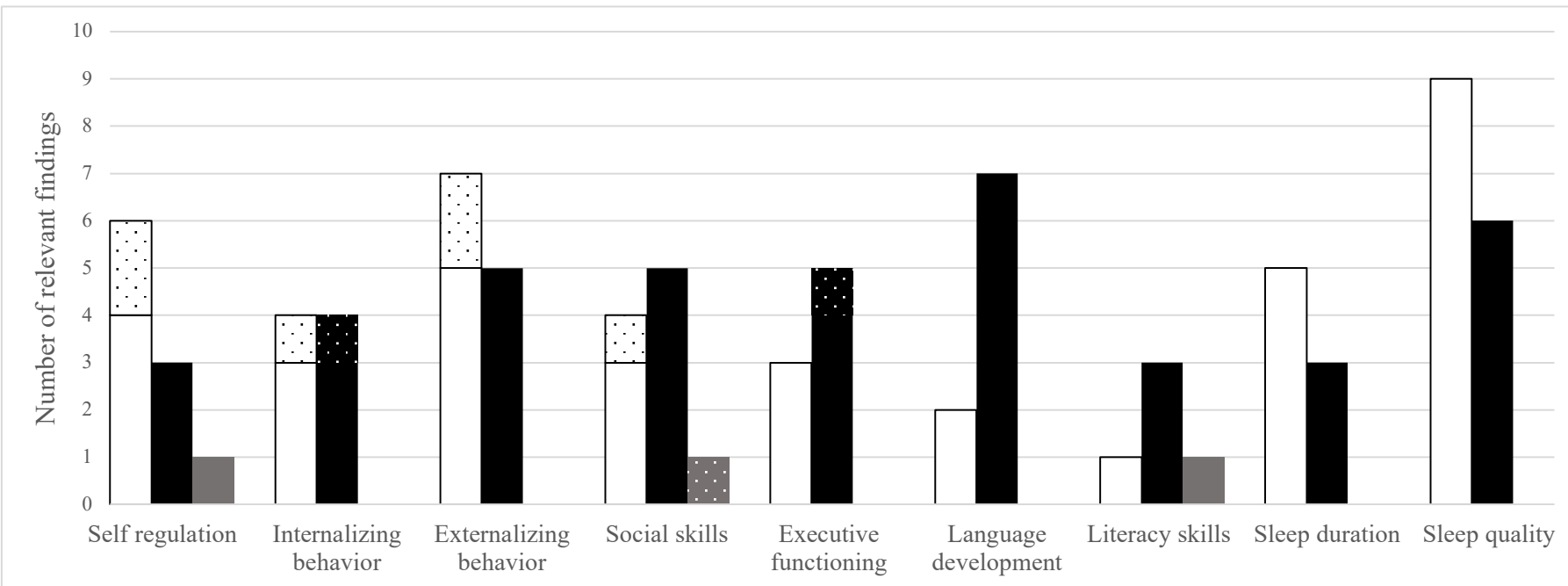

Note . White $=$ adverse association; black $=$ null association; grey $=$ beneficial association; dots denote studies that reported parental perceptions of problematic use by children rather than a measure of amount of use. 


\section{Figure 3}

Forest plot of correlations between amount of smartphone or tablet use and overall aggregated child-specific factors in young children

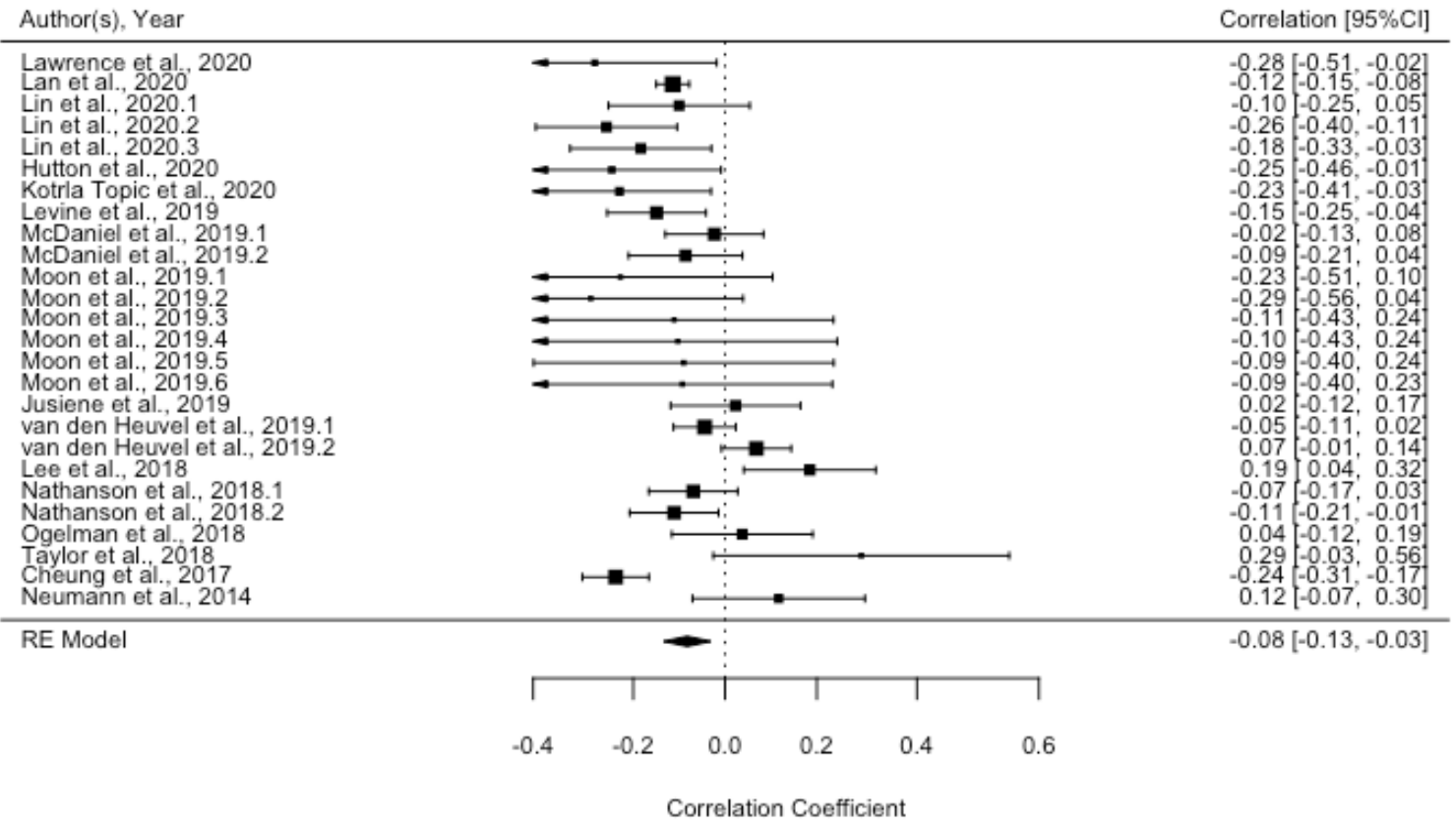


Figure 4

Forest plot of correlations between parental perceptions of problematic smartphone and tablet use and overall child-specific factors in young children

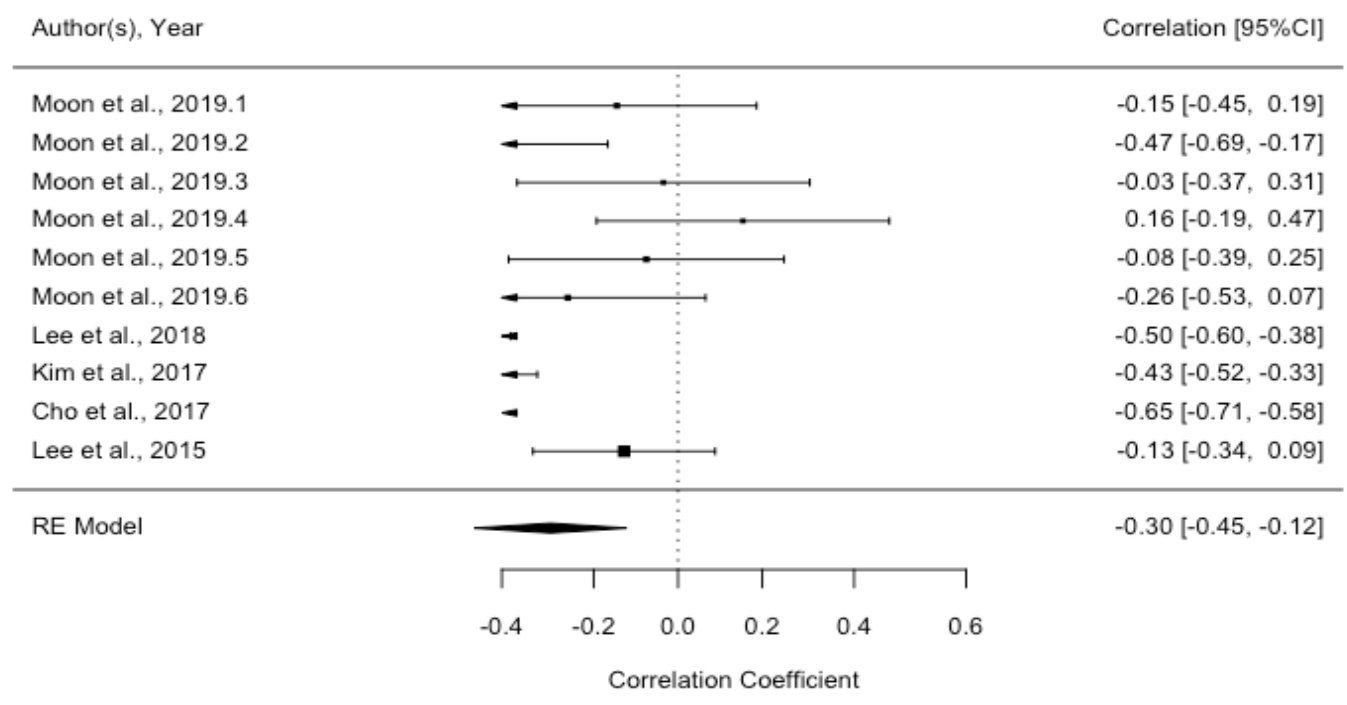

